\title{
Novel Cinnamoylated Flavoalkaloids Identified in Tea with Acetylcholinesterase Inhibition Effect
}

\author{
Rashmi Gaur, ${ }^{1}$ Jia-Ping Ke, ${ }^{1}$ Peng Zhang, ${ }^{1} \mathrm{Zi}$ Yang ${ }^{1}$, Guan-Hu Bao ${ }^{1, *}$ \\ ${ }^{1}$ Natural Products Laboratory, International Joint Laboratory of Tea Chemistry and Health \\ Effects, State Key Laboratory of Tea Plant Biology and Utilization, Anhui Agricultural \\ University, Hefei 230036, China
}

Corresponding author's name and address:

Guan-Hu Bao

E-mail address: baoguanhu@ahau.edu.cn; Phone: 86-551-65786401, Fax: 86-551-65786765;

State Key Laboratory of Tea Plant Biology and Utilization, Anhui Agricultural University, Hefei 230036, China

List of supporting information

Figure Supporting 1. ${ }^{1} \mathrm{H}$ NMR of compound 1 in MeOD.

Figure Supporting 2. ${ }^{13} \mathrm{C}$ NMR of compound 1 in MeOD

Figure Supporting 3. COSY of compound 1 in $\mathrm{MeOD}$

Figure Supporting 4. HSQC of compound 1 in MeOD

Figure Supporting 5. HMBC of compound 1 in MeOD.

Figure Supporting 6. ${ }^{1} \mathrm{H}$ NMR of compound 2 in DMSO- $\mathrm{d}_{6}$.

Figure Supporting 7. ${ }^{13} \mathrm{C}$ NMR of compound 2 in DMSO-d 6 .

Figure Supporting 8. COSY of compound 2 in DMSO- $\mathrm{d}_{6}$.

Figure Supporting 9. HSQC of compound 2 in DMSO-d $\mathrm{d}_{6}$.

Figure Supporting 10. HMBC of compound 2 in DMSO- $\mathrm{d}_{6}$. 
Figure Supporting 11. ROESY of compound 2 inDMSO- $\mathrm{d}_{6}$.

Figure Supporting 12. ${ }^{1} \mathrm{H}$ NMR of compound 3 in DMSO- $\mathrm{d}_{6}$.

Figure Supporting 13. ${ }^{13} \mathrm{C}$ NMR of compound 3 in DMSO-d $\mathrm{d}_{6}$.

Figure Supporting 14. HSQC of compound 3 in DMSO-d $\mathrm{d}_{6}$.

Figure Supporting 15. HMBC of compound 3 in DMSO- $\mathrm{d}_{6}$.

Figure Supporting 16. ROESY of compound 3 in DMSO-d $\mathrm{d}_{6}$.

Figure Supporting 17. ${ }^{1} \mathrm{H}$ NMR of compound 4 in DMSO- $\mathrm{d}_{6}$.

Figure Supporting 18. ${ }^{13} \mathrm{C}$ NMR of compound 4 in DMSO-d $\mathrm{d}_{6}$.

Figure Supporting 19. COSY of compound 4 in DMSO- $\mathrm{d}_{6}$.

Figure Supporting 20. ROESY of compound 4 in DMSO-d $\mathrm{d}_{6}$.

Figure Supporting 21. ${ }^{1} \mathrm{H}$ NMR of compound 5 in DMSO- $\mathrm{d}_{6}$.

Figure Supporting 22. ${ }^{13} \mathrm{C}$ NMR of compound 5 in DMSO-d $\mathrm{d}_{6}$.

Figure Supporting 23. COSY of compound 5 in DMSO-d $\mathrm{d}_{6}$.

Figure Supporting 24. Infrared spectrum of compound 1.

Figure Supporting 25. Infrared spectrum of compound 2.

Figure Supporting 26. Infrared spectrum of compound 3.

Figure Supporting 27. Infrared spectrum of compound 4.

Figure Supporting 28. Infrared spectrum of compound 5.

Figure Supporting 29. HPLC Preparation of compound 2-5 with UV detection at the waveleght $278 \mathrm{~nm}$.

Figure Supporting 30. UV of Compound 1

Figure Supporting 31. UV of Compound 2

Figure Supporting 32. UV of Compound 3 
Figure Supporting 33. UV of Compound 4

Figure Supporting 34. UV of Compound 5

Figure Supporting 35. MS of Compound 1

Figure Supporting 36. MS of Compound 2

Figure Supporting 37. MS of Compound 3

Figure Supporting 38. MS of Compound 4

Figure Supporting 39. MS of Compound 5

Table Supporting 1. Preparative method for compound 2-5 by HPLC. 


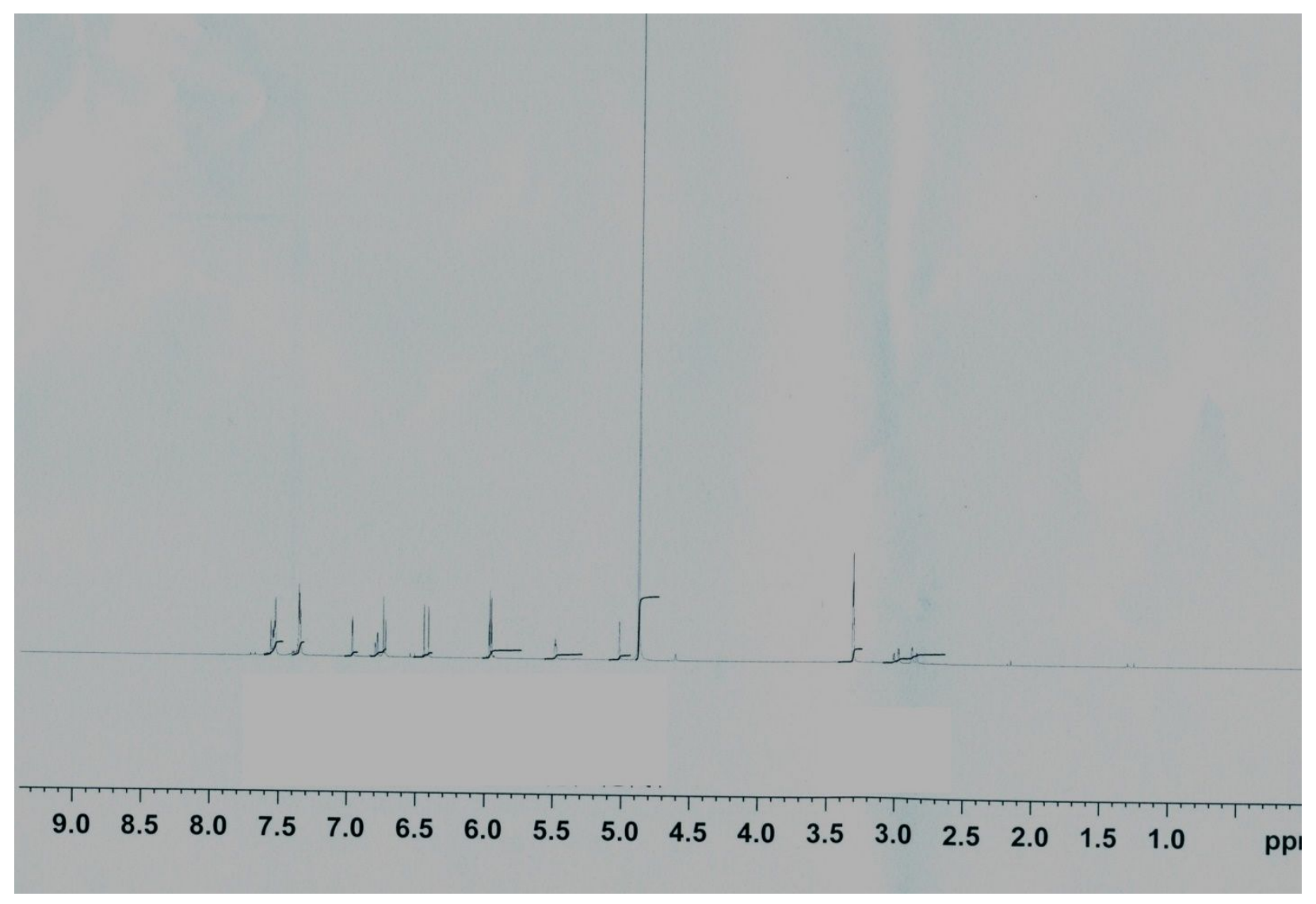

Figure Supporting 1. ${ }^{1} \mathrm{H}$ NMR of compound 1 in MeOD. 


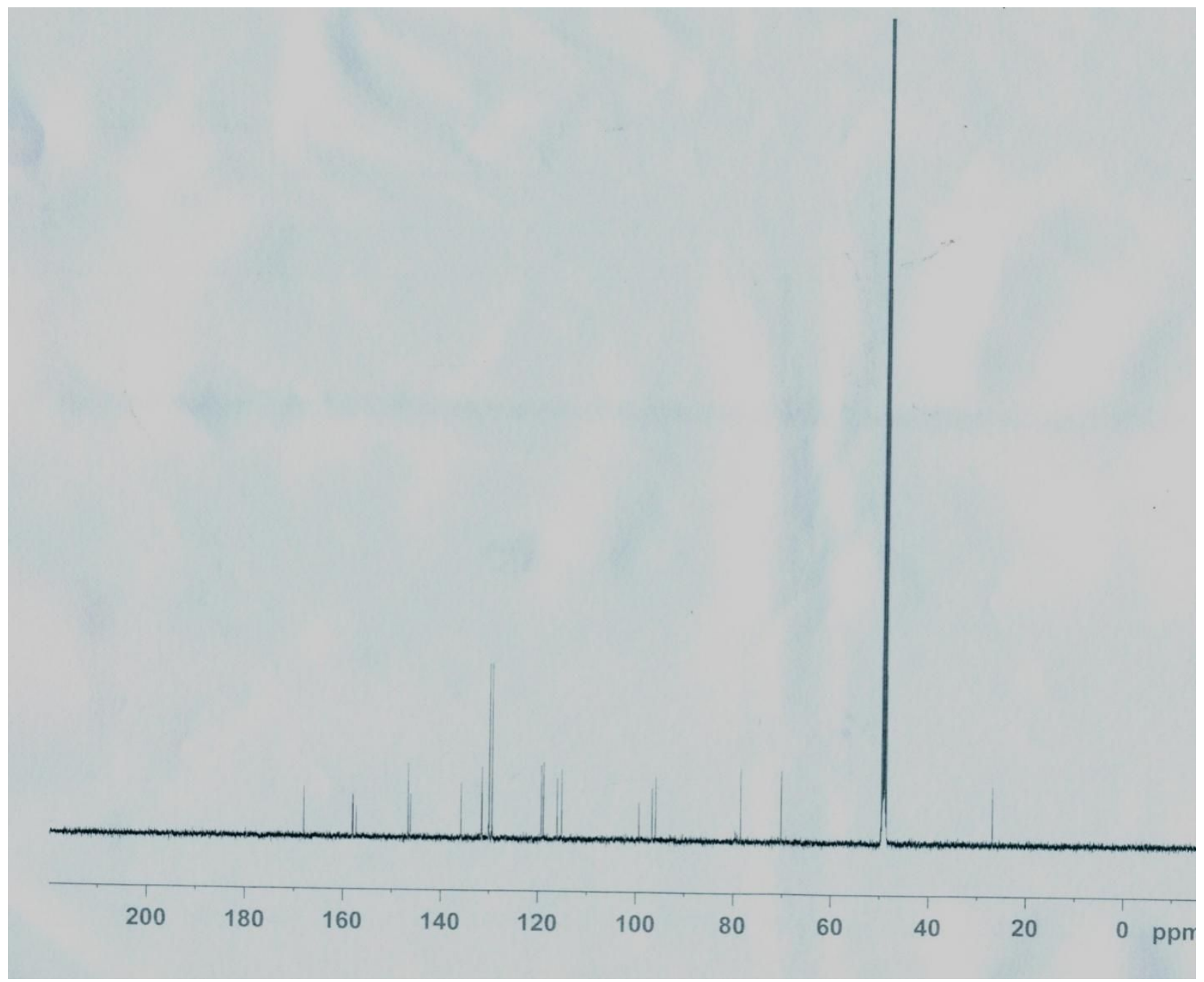

Figure Supporting 2. ${ }^{13} \mathrm{C}$ NMR of compound 1 in MeOD 


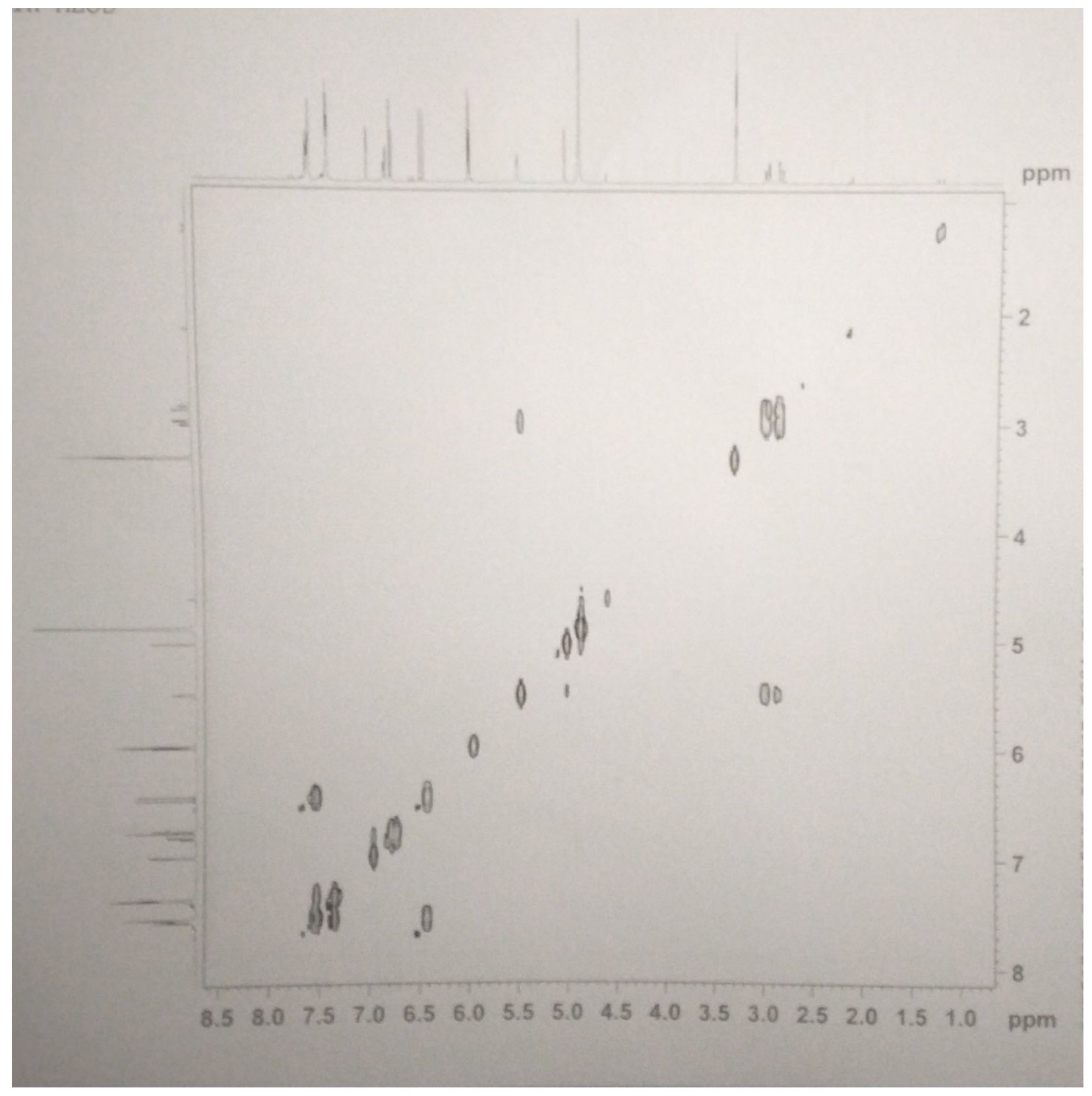

Figure Supporting 3. COSY of compound 1 in MeOD 


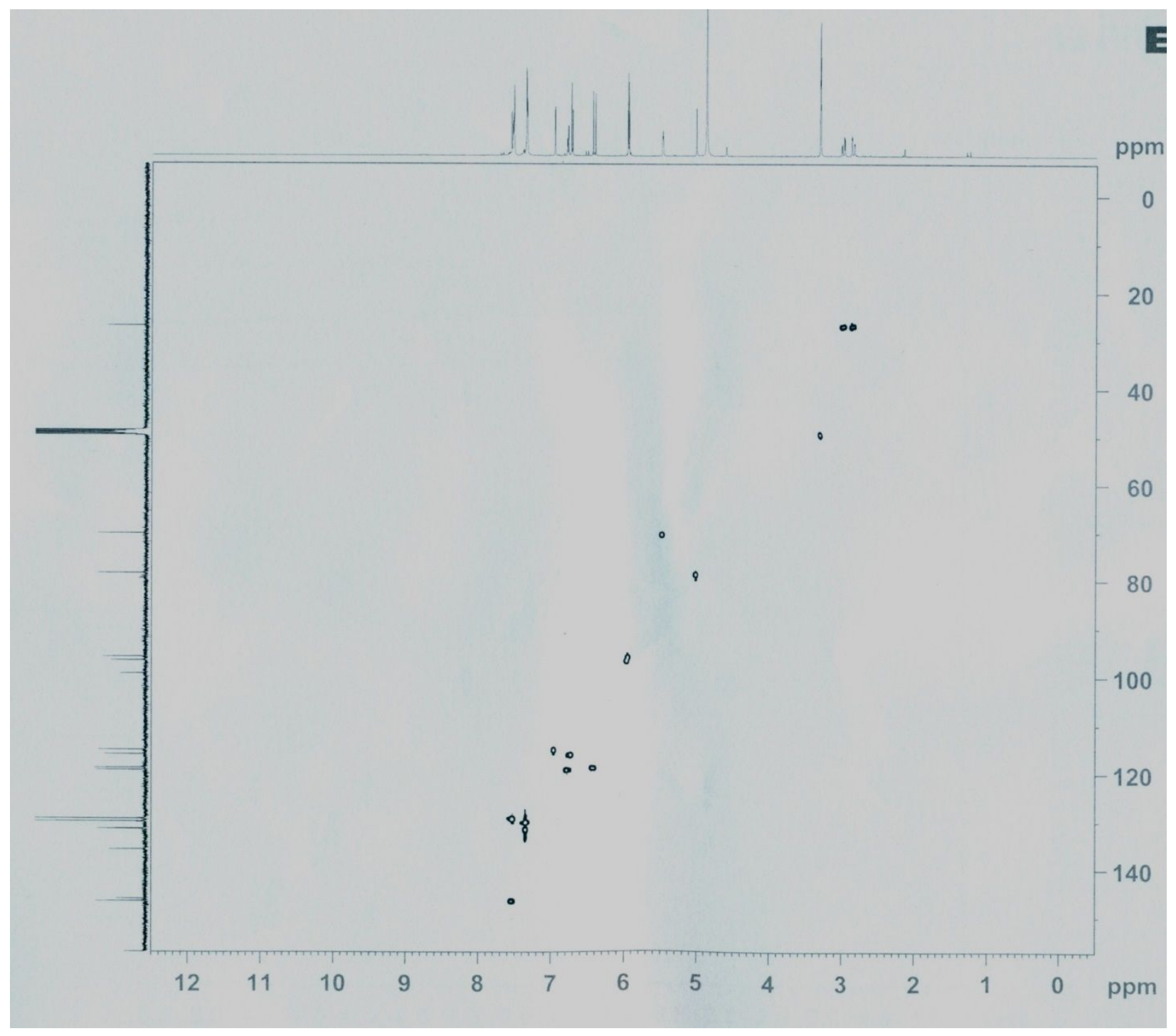

Figure Supporting 4. HSQC of compound 1 in $\mathrm{MeOD}$ 


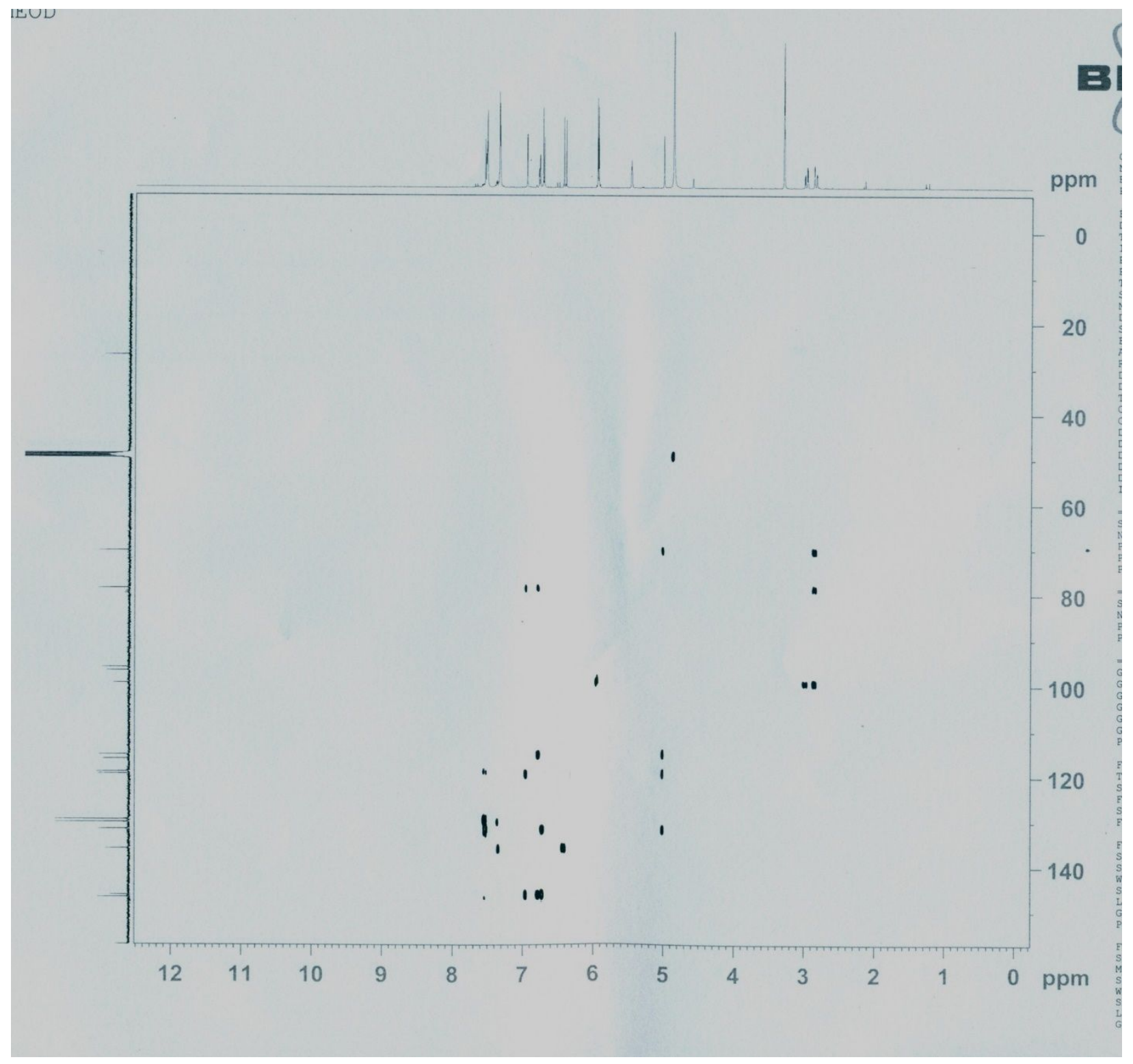

Figure Supporting 5. HMBC of compound 1 in MeOD. 


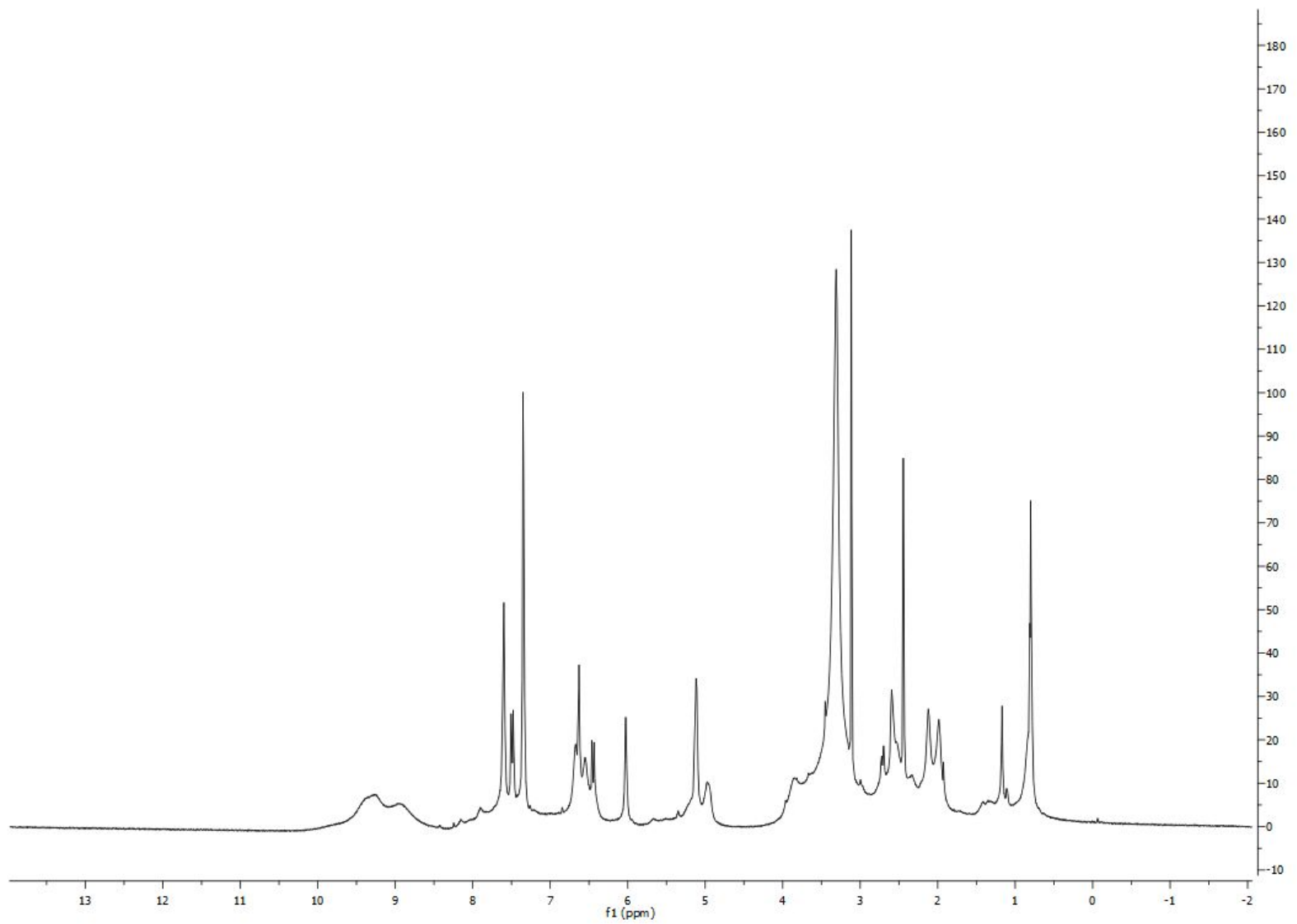

Figure Supporting 6. ${ }^{1} \mathrm{H}$ NMR of compound 2 in DMSO- $\mathrm{d}_{6}$. 


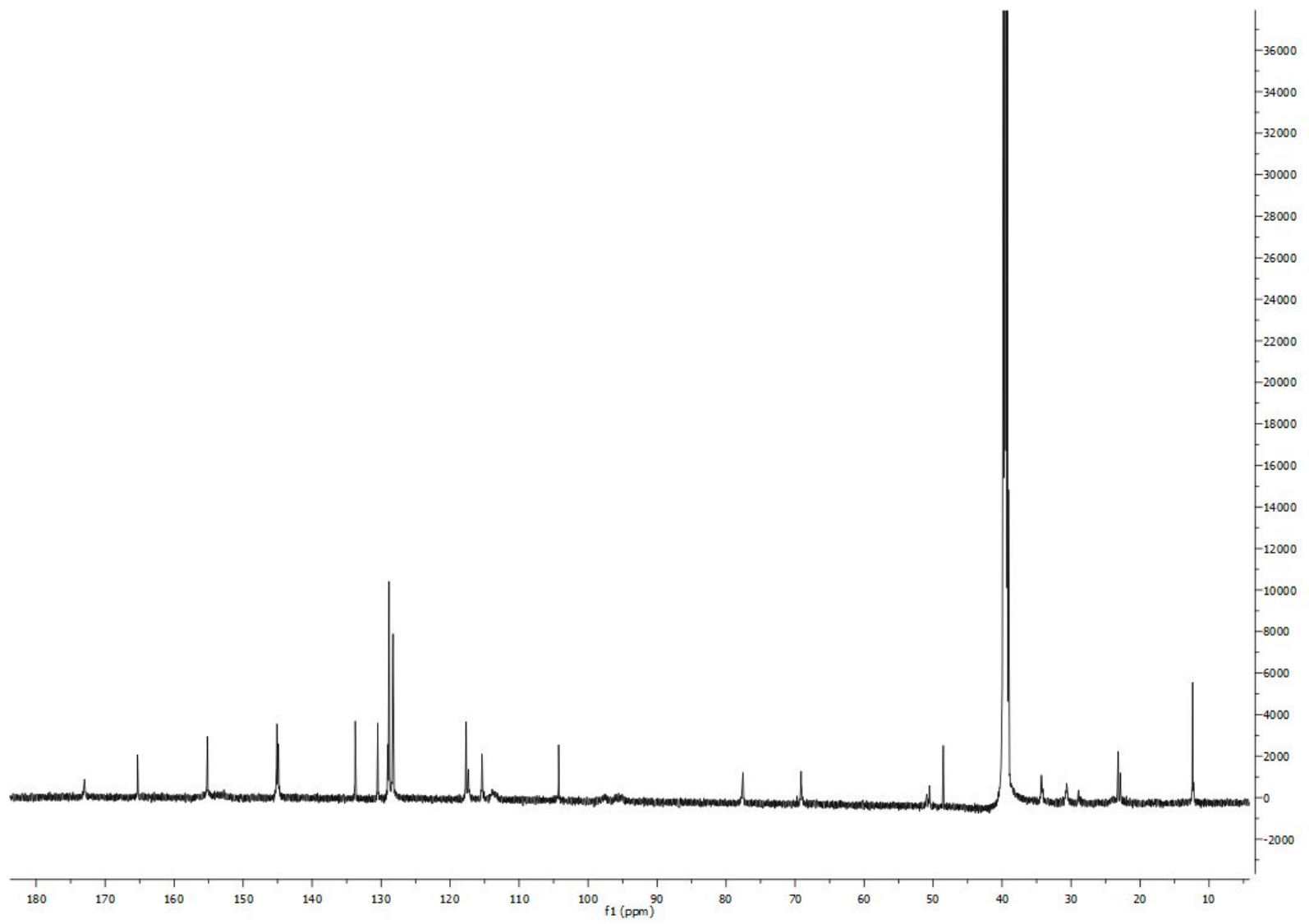

Figure Supporting 7. ${ }^{13} \mathrm{C}$ NMR of compound 2 in DMSO- $\mathrm{d}_{6}$. 


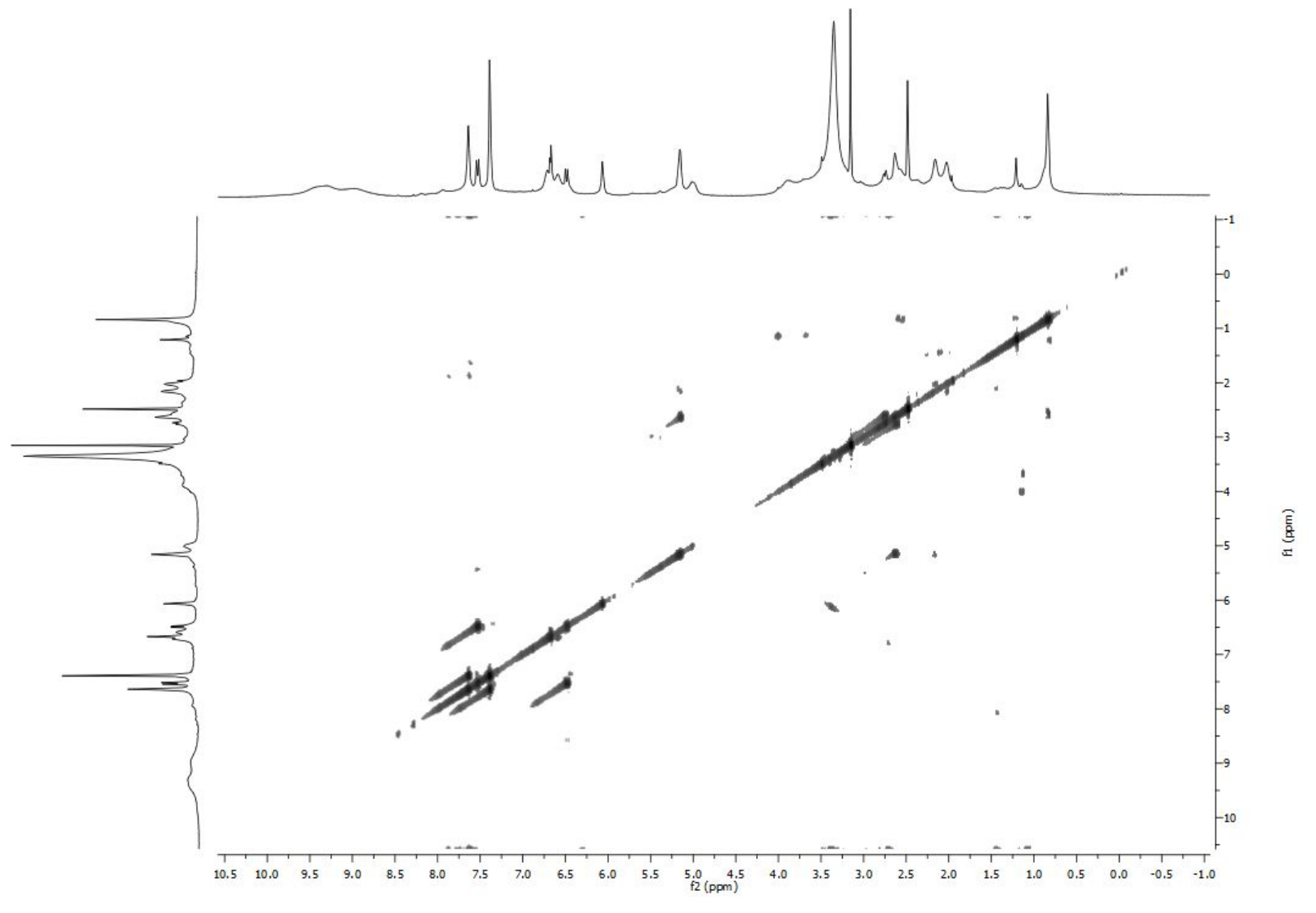

Figure Supporting 8. COSY of compound 2 in DMSO- $\mathrm{d}_{6}$. 


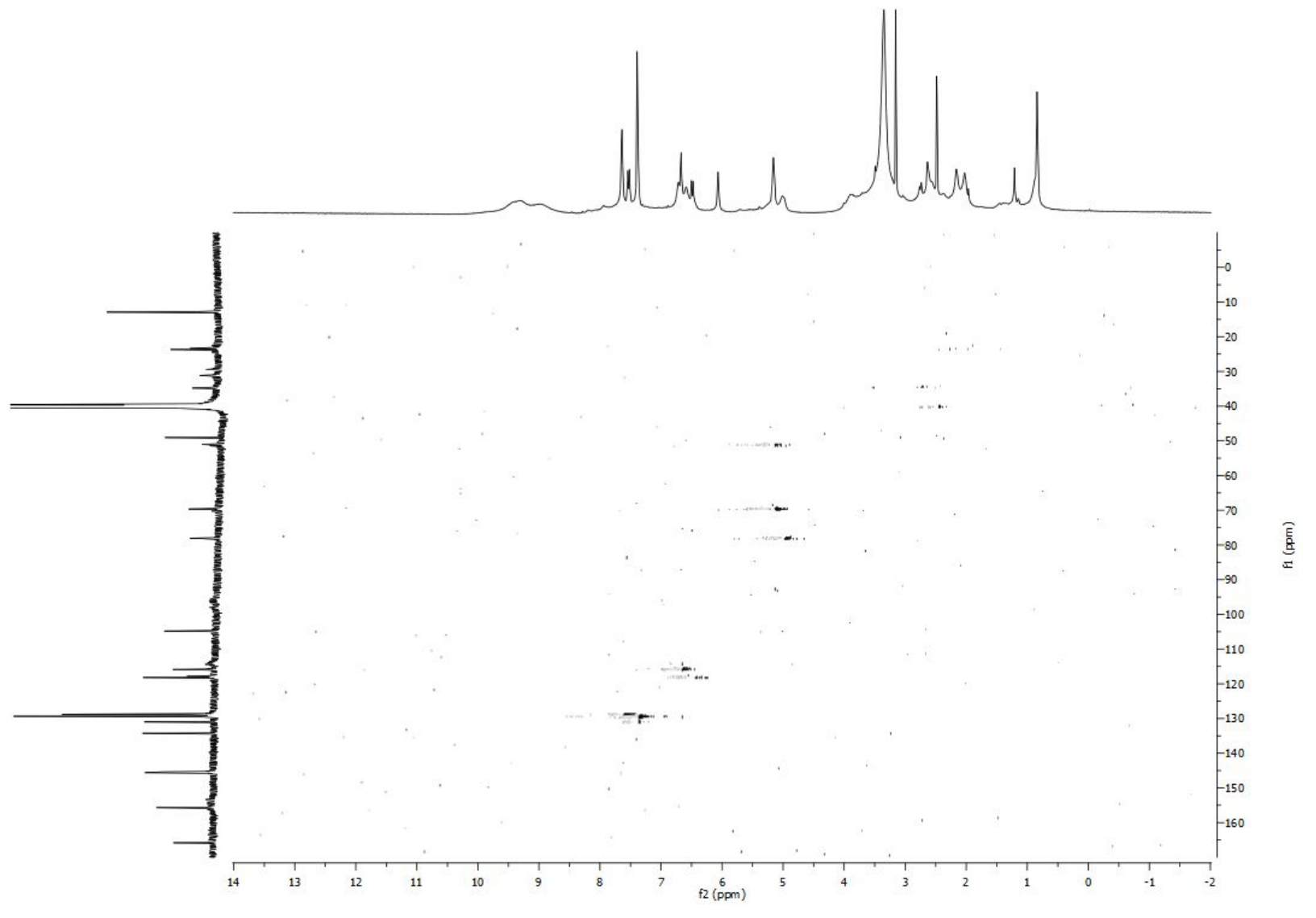

Figure Supporting 9. HSQC of compound 2 in DMSO- $\mathrm{d}_{6}$. 


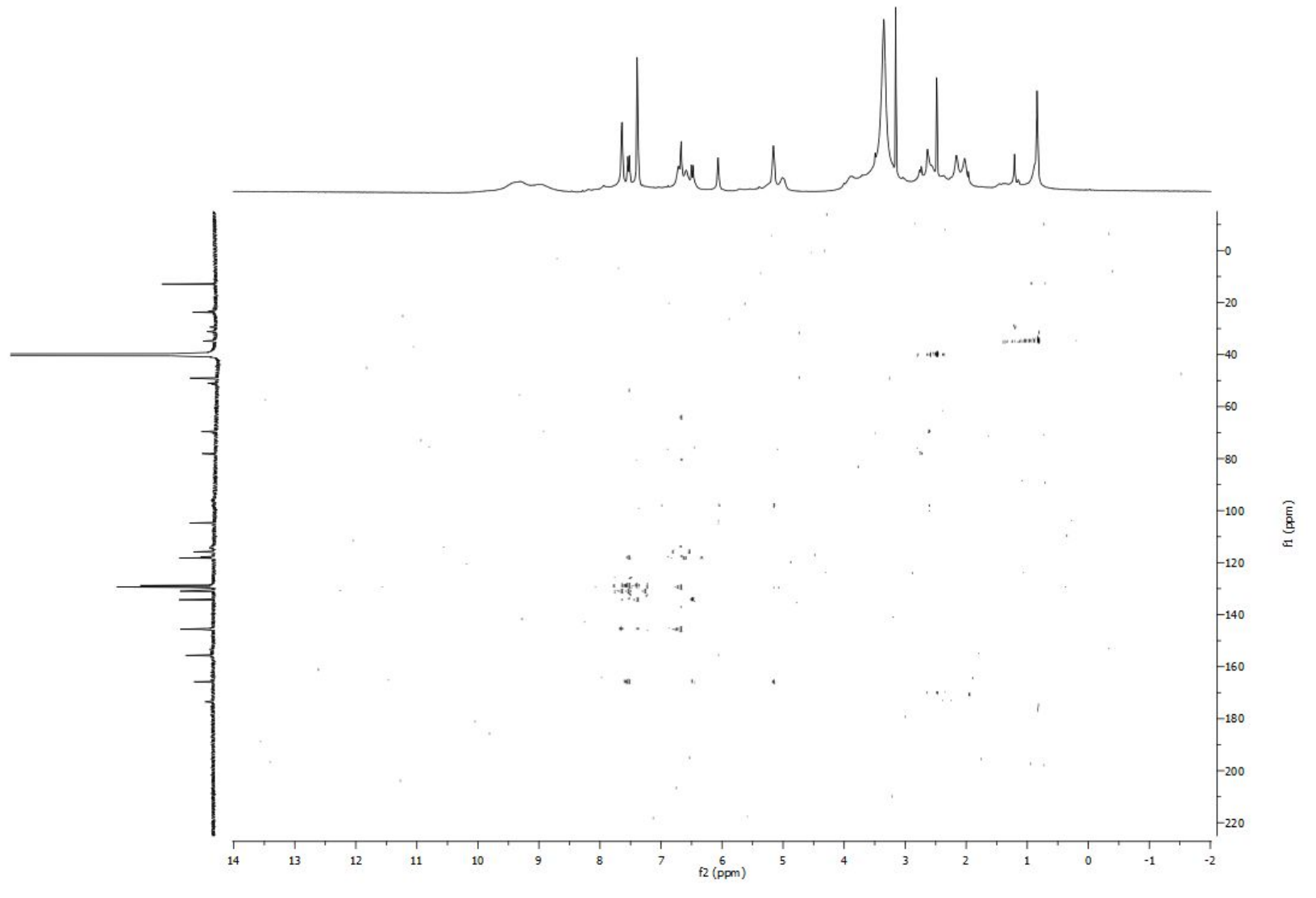

Figure Supporting 10. HMBC of compound 2 in DMSO- $\mathrm{d}_{6}$. 


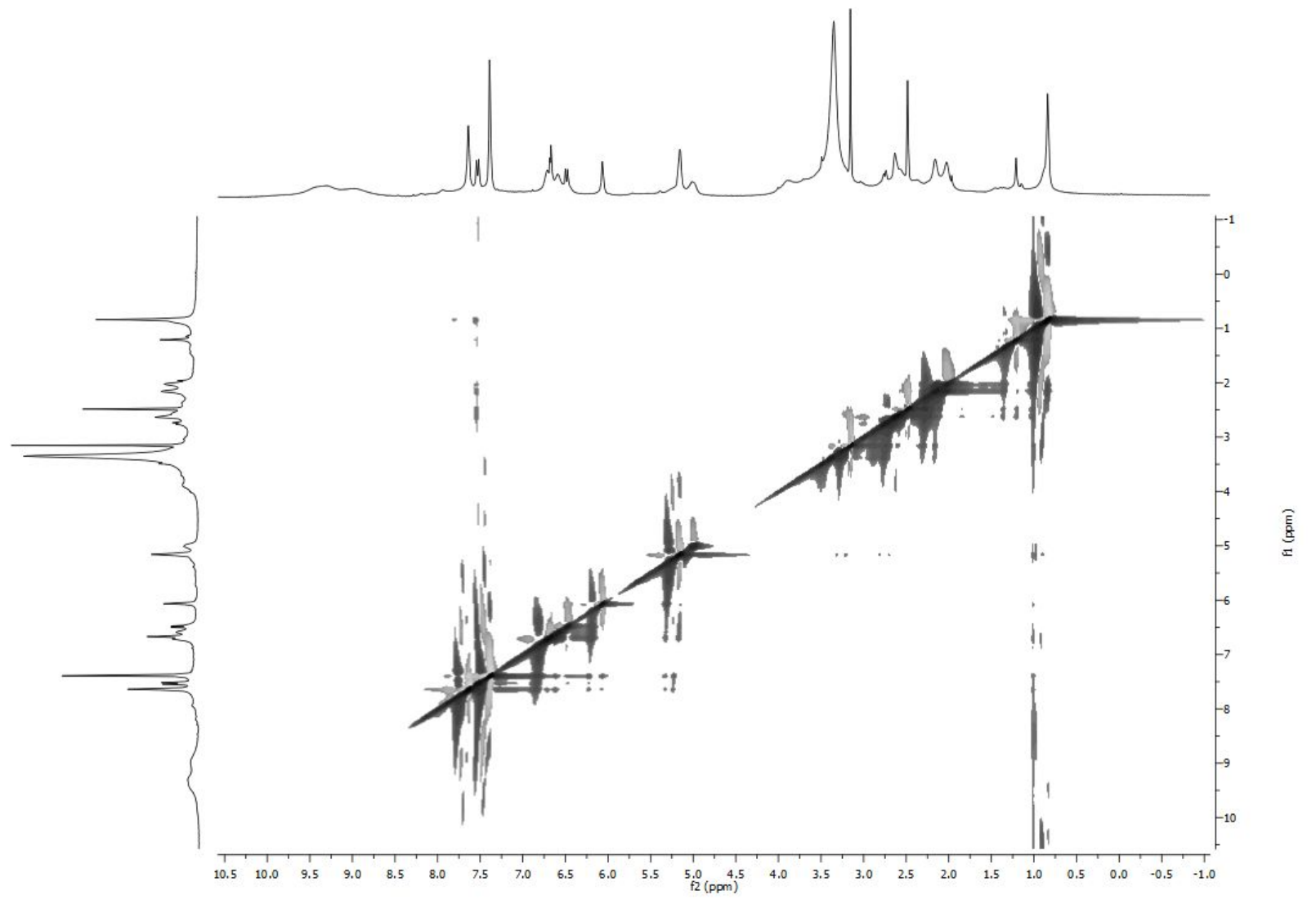

Figure Supporting 11. ROESY of compound 2 inDMSO- $\mathrm{d}_{6}$. 


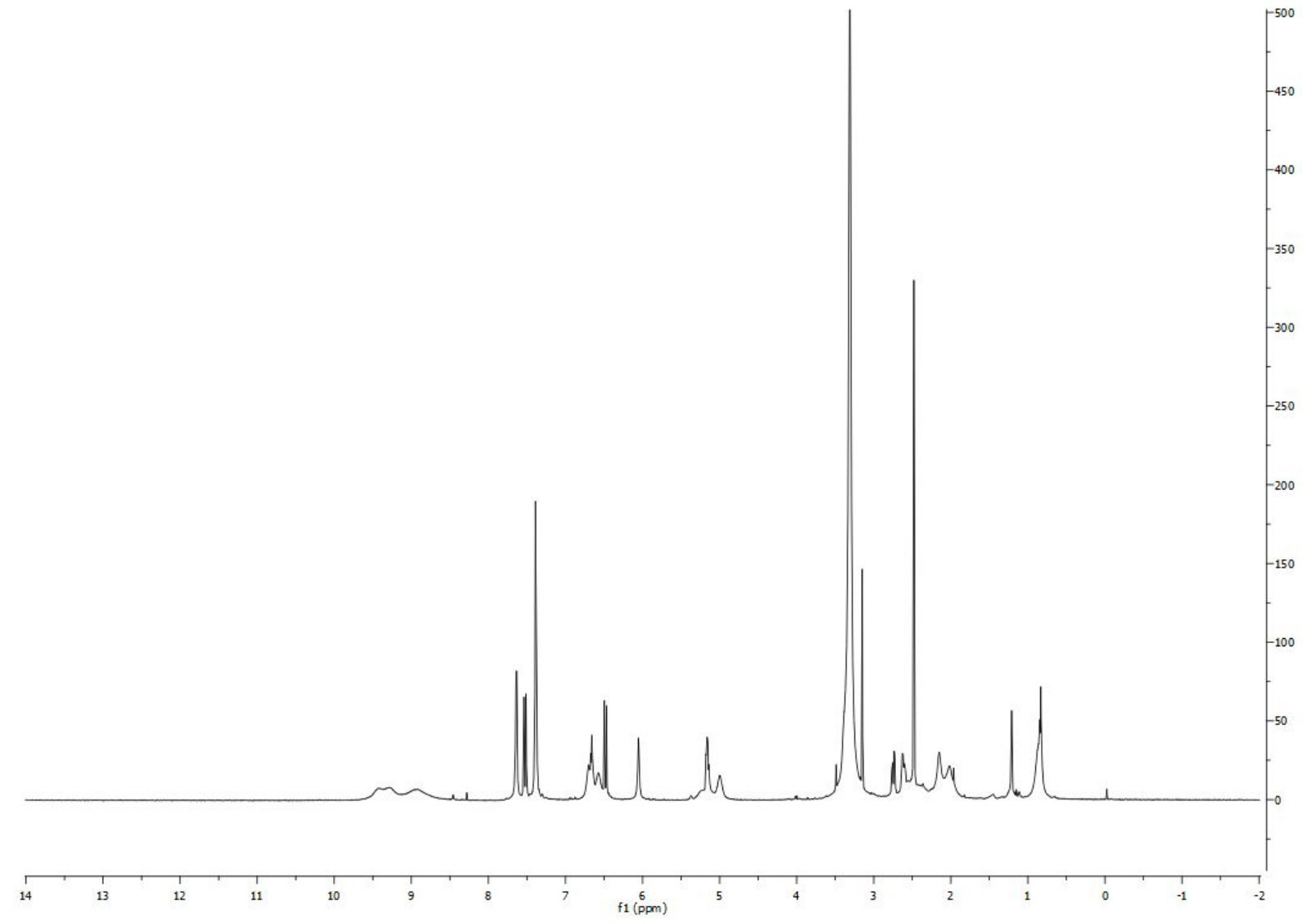

Figure Supporting 12. ${ }^{1} \mathrm{H}$ NMR of compound 3 in $\mathrm{DMSO}_{6}$. 


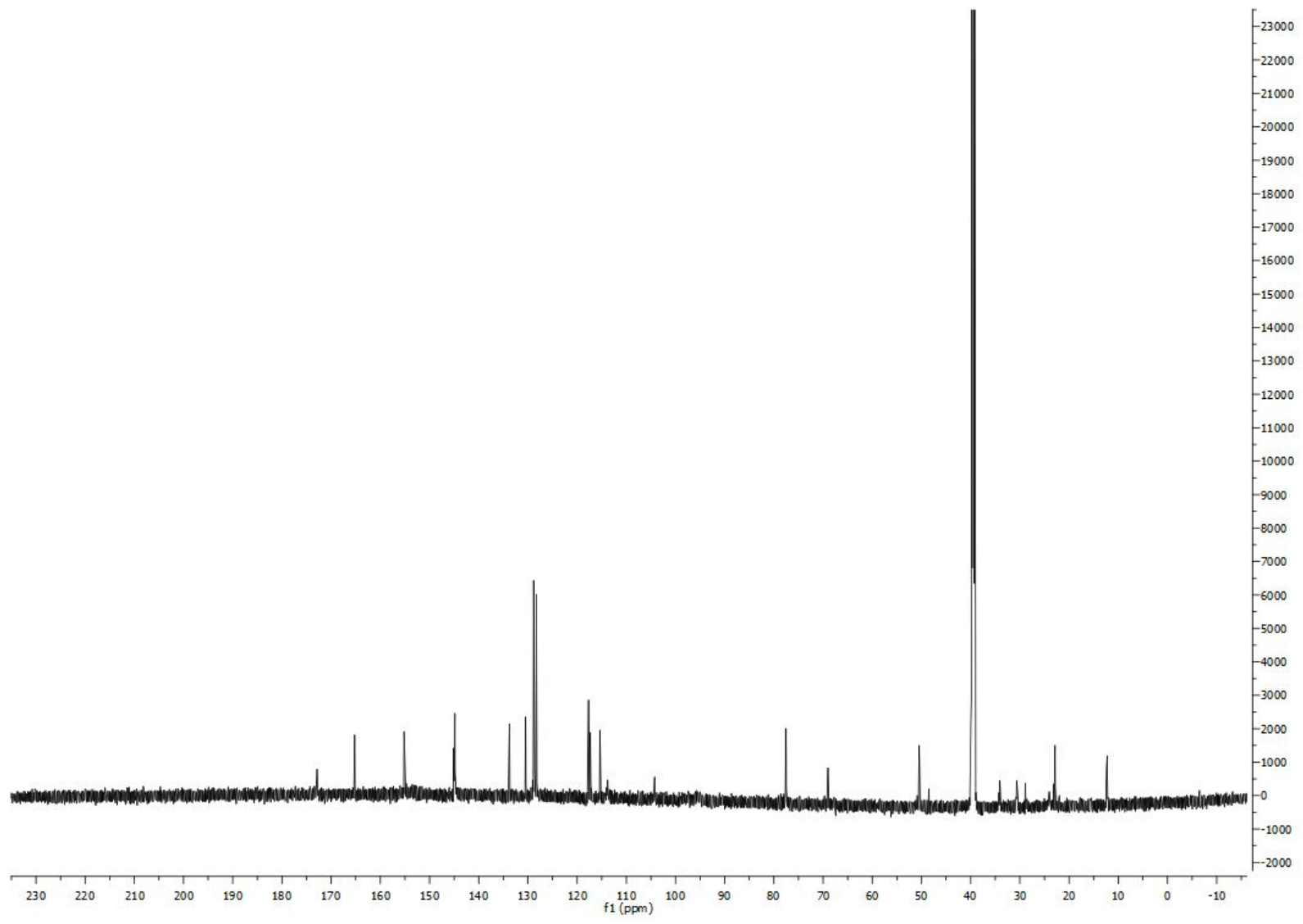

Figure Supporting 13. ${ }^{13} \mathrm{C}$ NMR of compound 3 in DMSO- $\mathrm{d}_{6}$. 


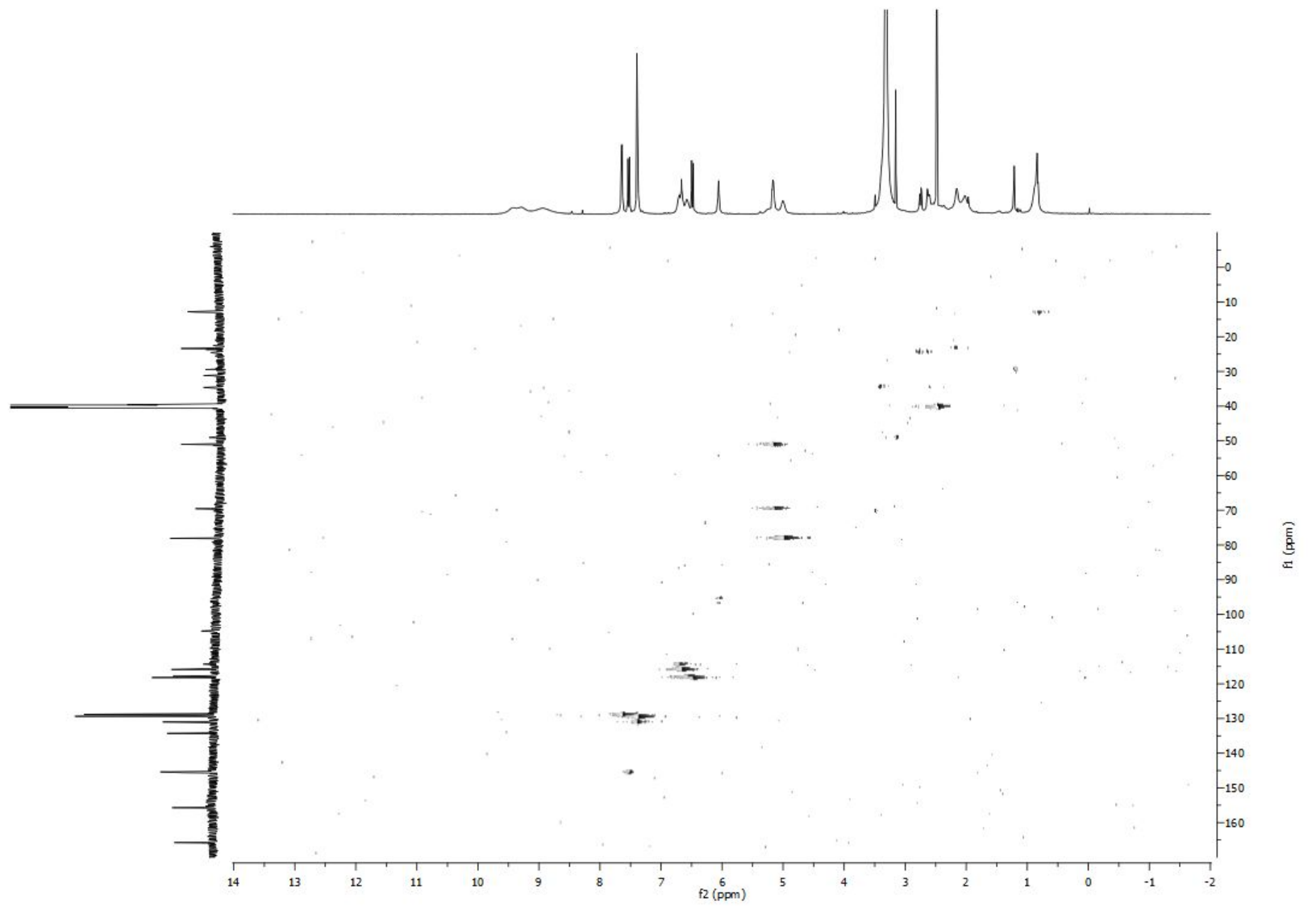

Figure Supporting 14. HSQC of compound 3 in DMSO- $\mathrm{d}_{6}$. 


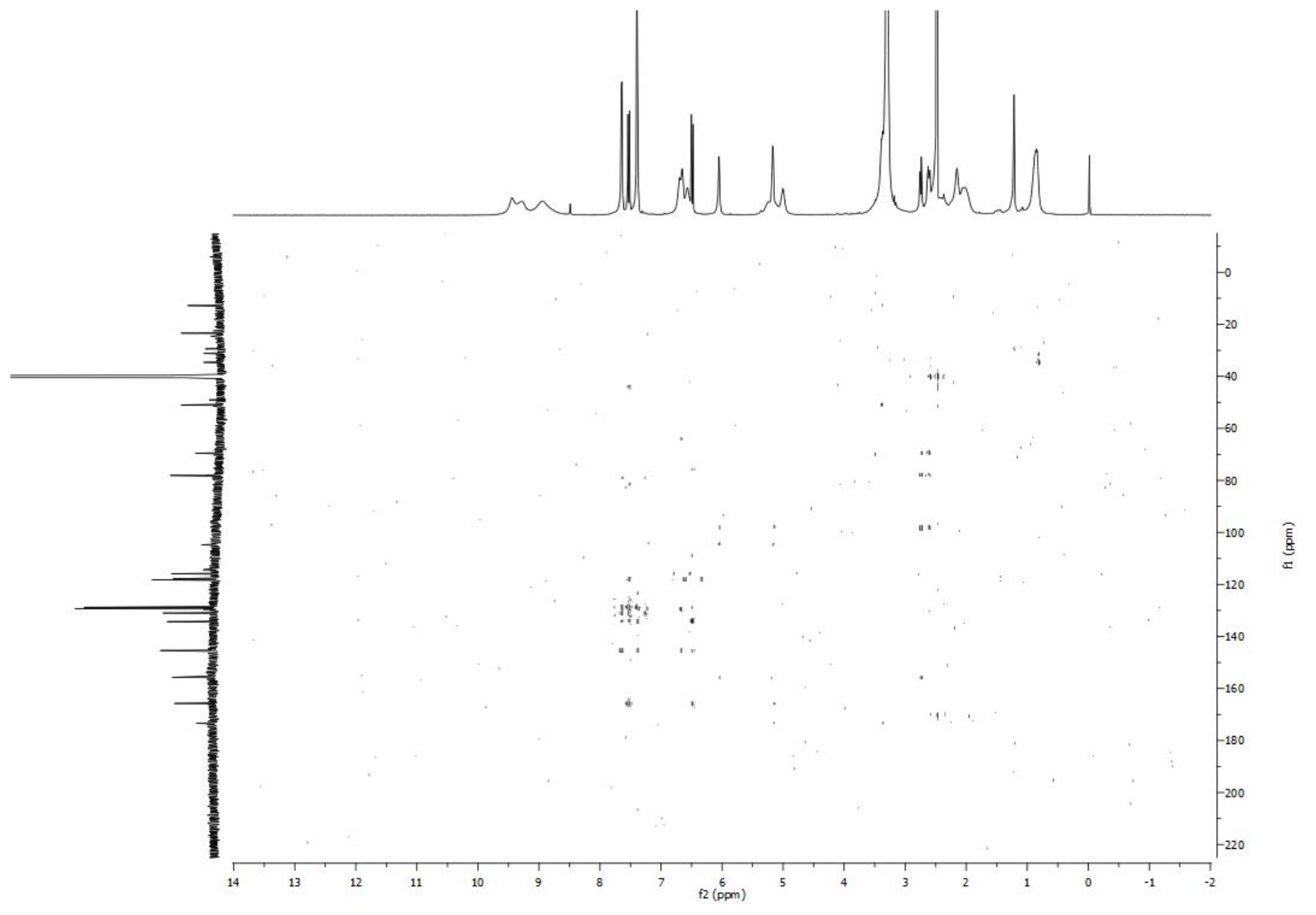

Figure Supporting 15. HMBC of compound 3 in DMSO- $\mathrm{d}_{6}$. 


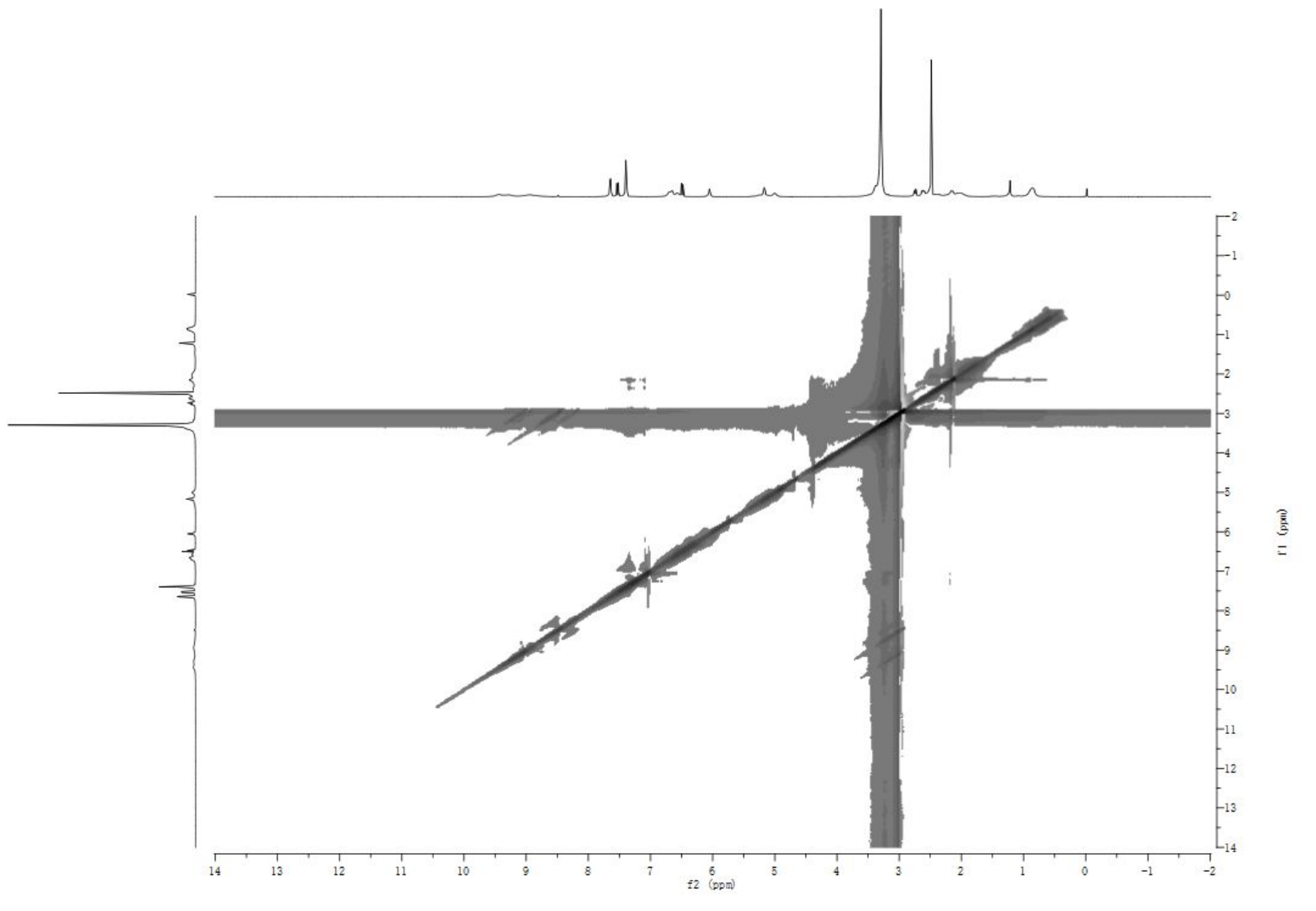

Figure Supporting 16. ROESY of compound 3 in DMSO-d $\mathrm{D}_{6}$. 


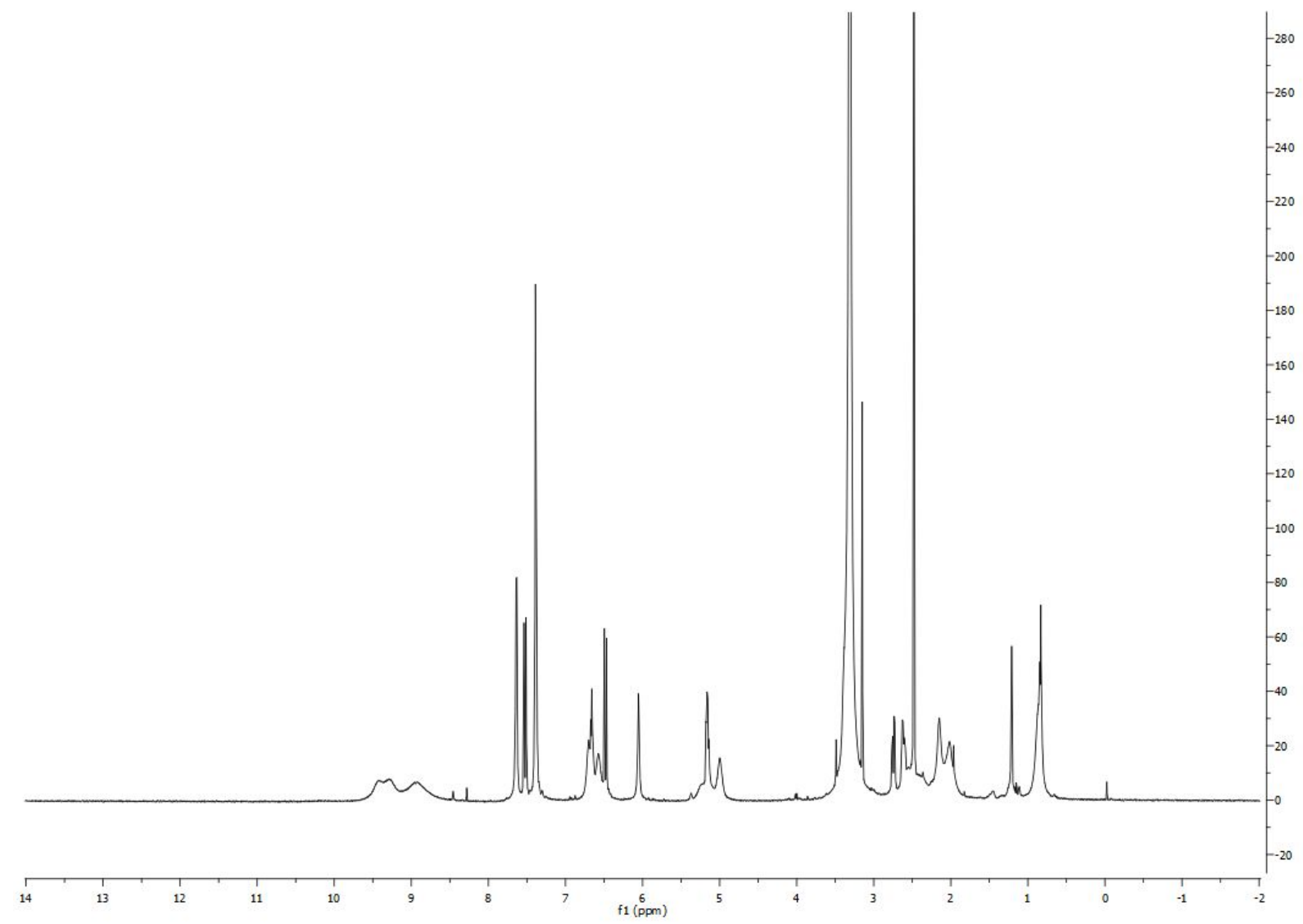

Figure Supporting 17. ${ }^{1} \mathrm{H}$ NMR of compound 4 in $\mathrm{DMSO}_{6}$. 


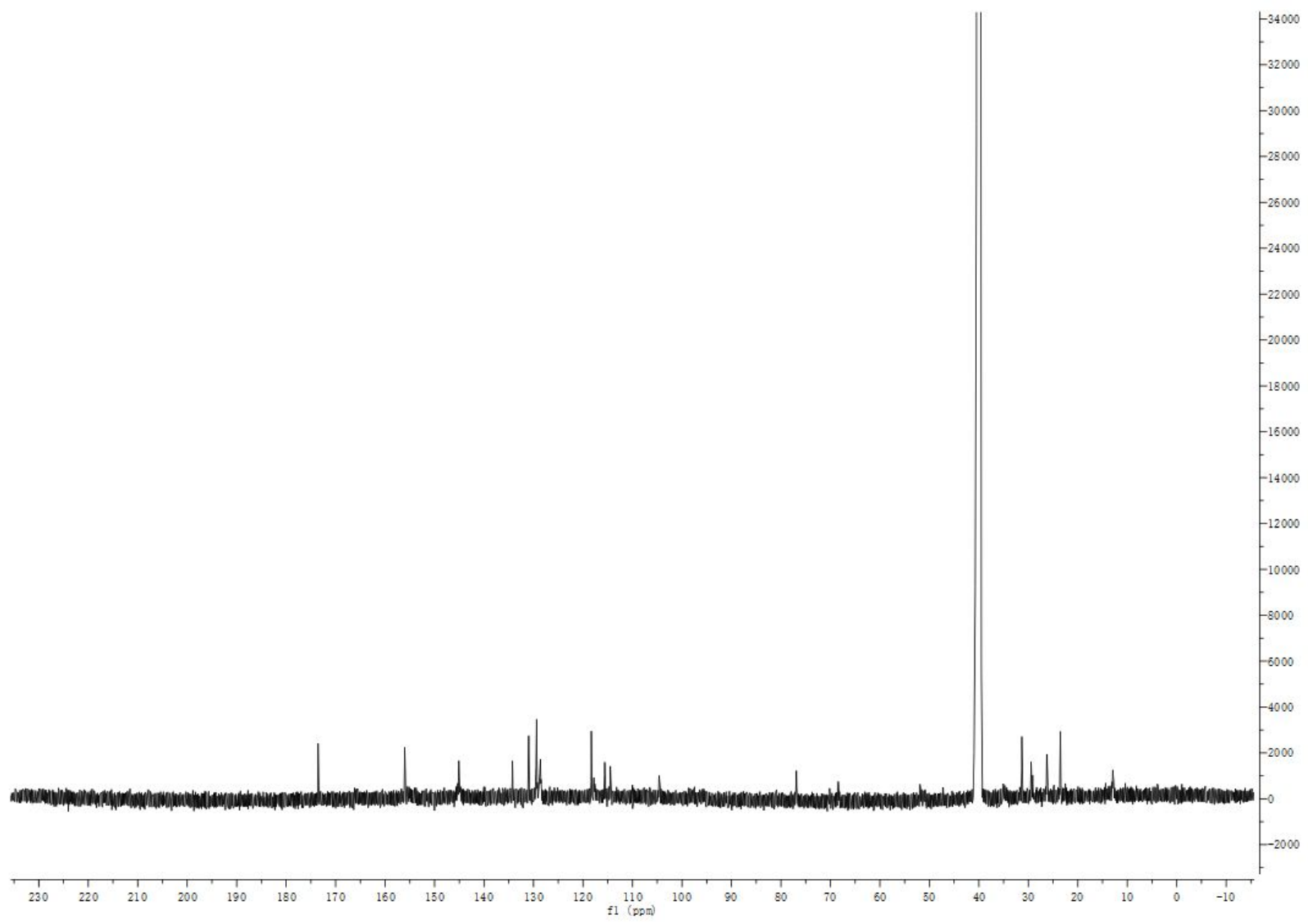

Figure Supporting 18. ${ }^{13} \mathrm{C}$ NMR of compound 4 in DMSO- $\mathrm{d}_{6}$. 


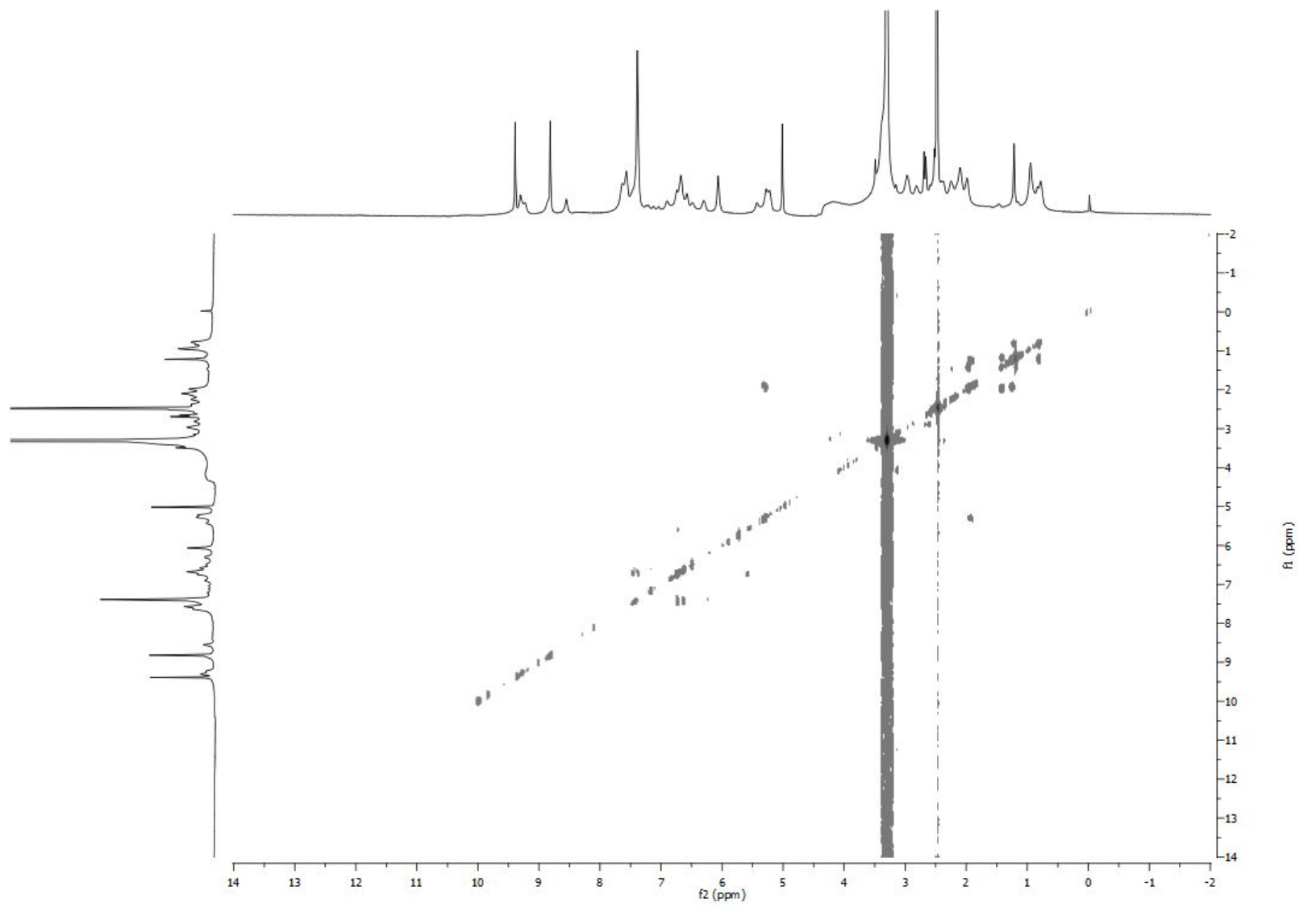

Figure Supporting 19. COSY of compound 4 in DMSO-d $\mathrm{d}_{6}$. 


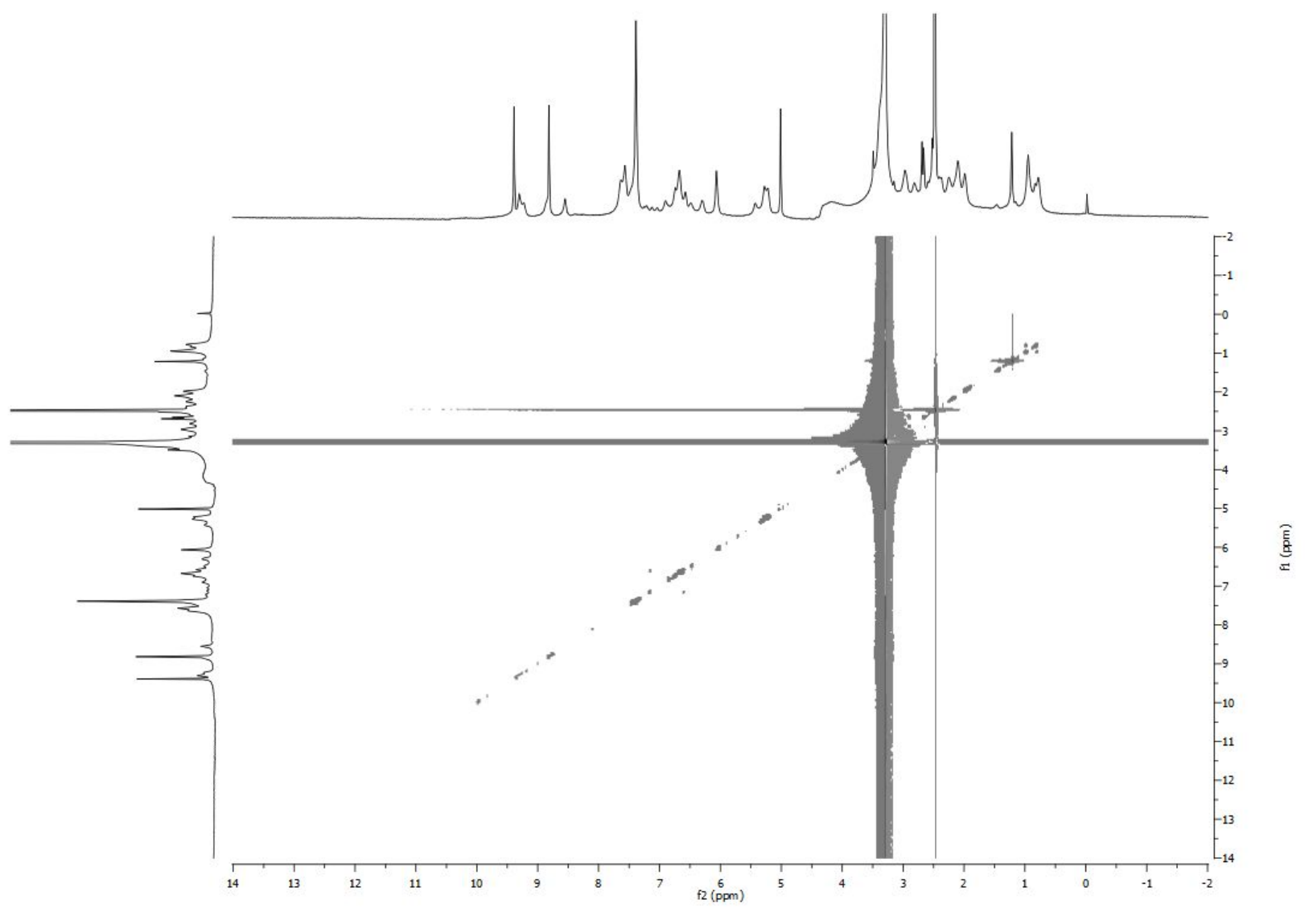

Figure Supporting 20. ROESY of compound 4 in DMSO-d 6 . 


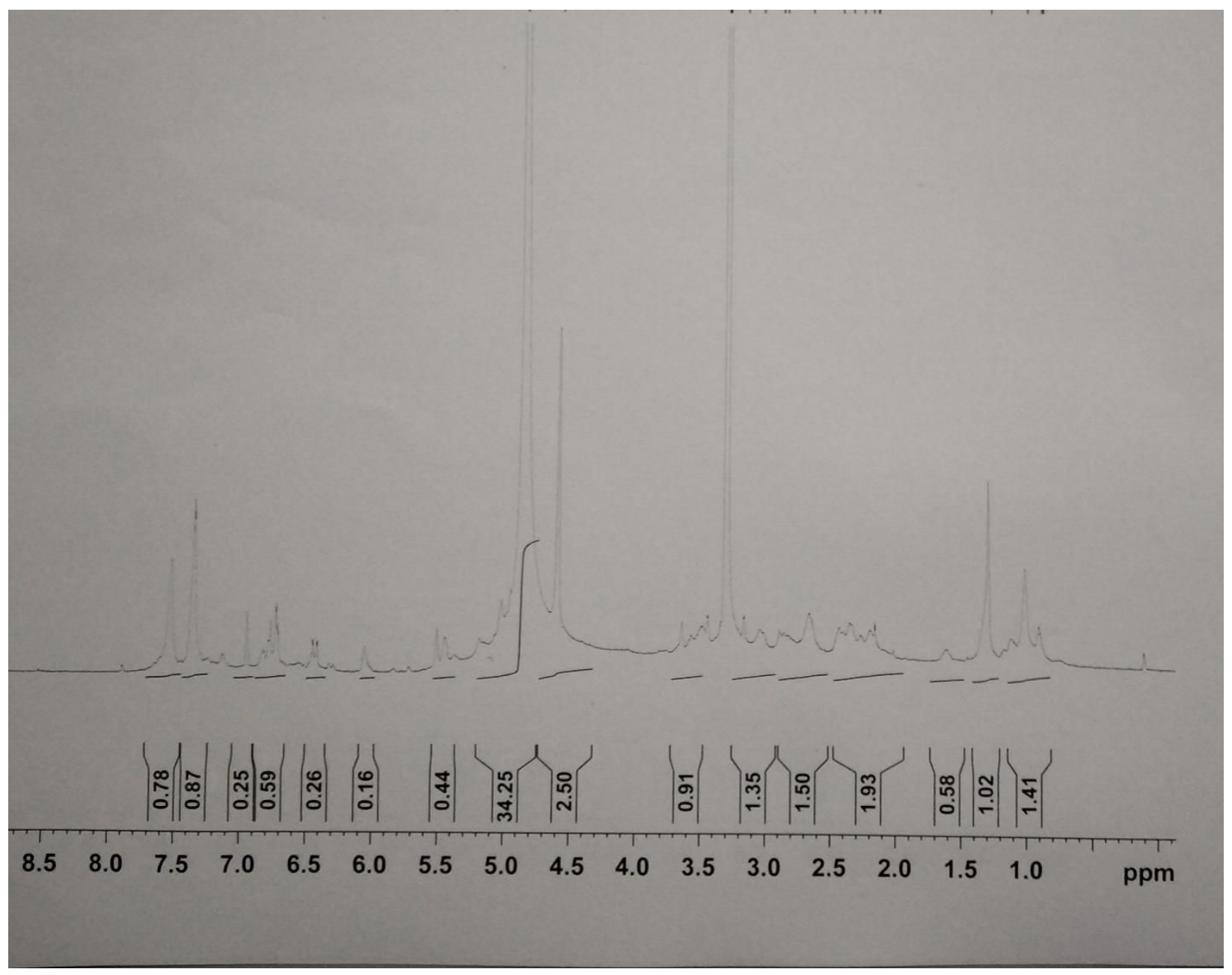

Figure Supporting 21. ${ }^{1} \mathrm{H}$ NMR of compound 5 in DMSO-d 6 . 


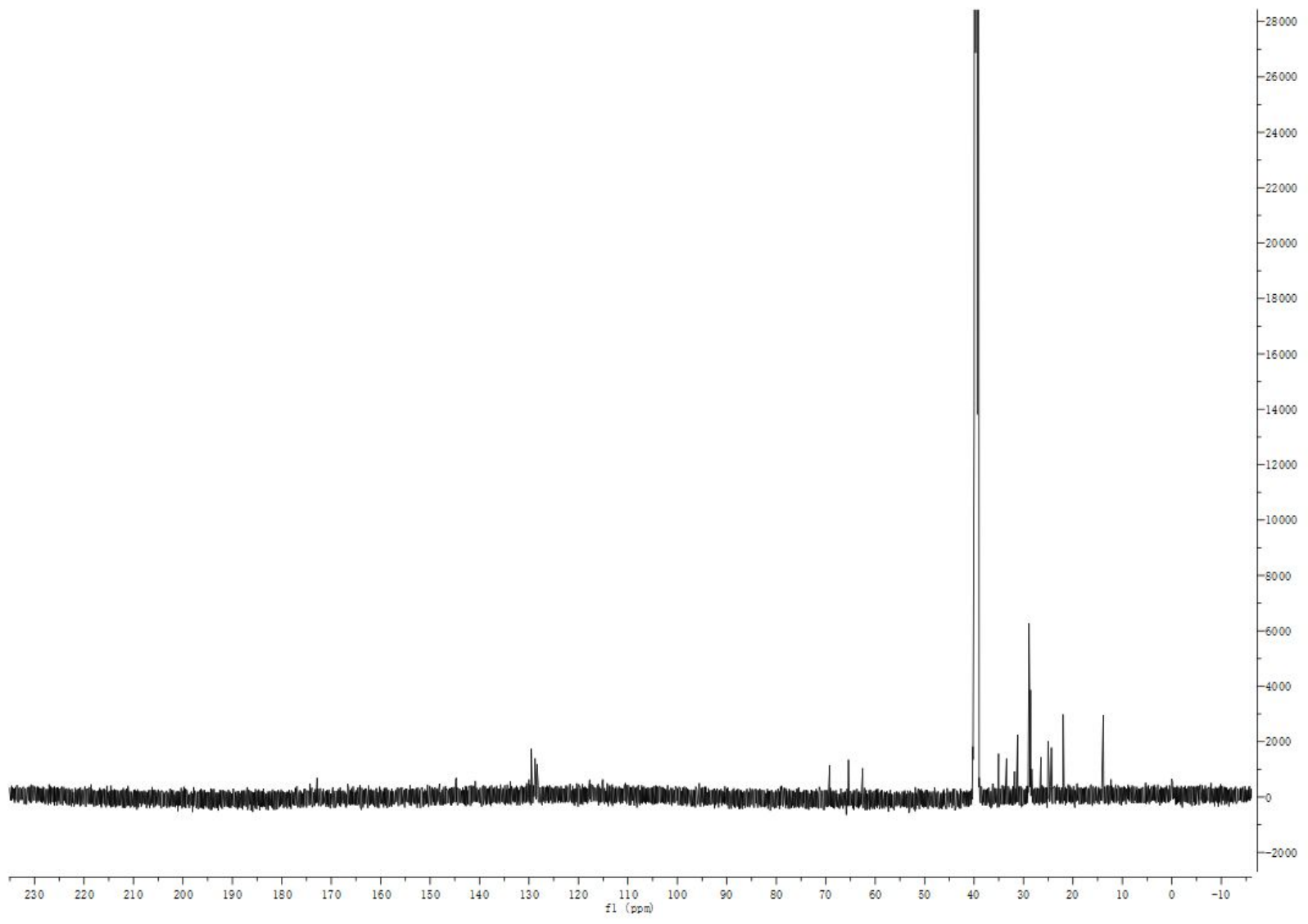

Figure Supporting 22. ${ }^{13} \mathrm{C}$ NMR of compound 5 in DMSO- $\mathrm{d}_{6}$. 


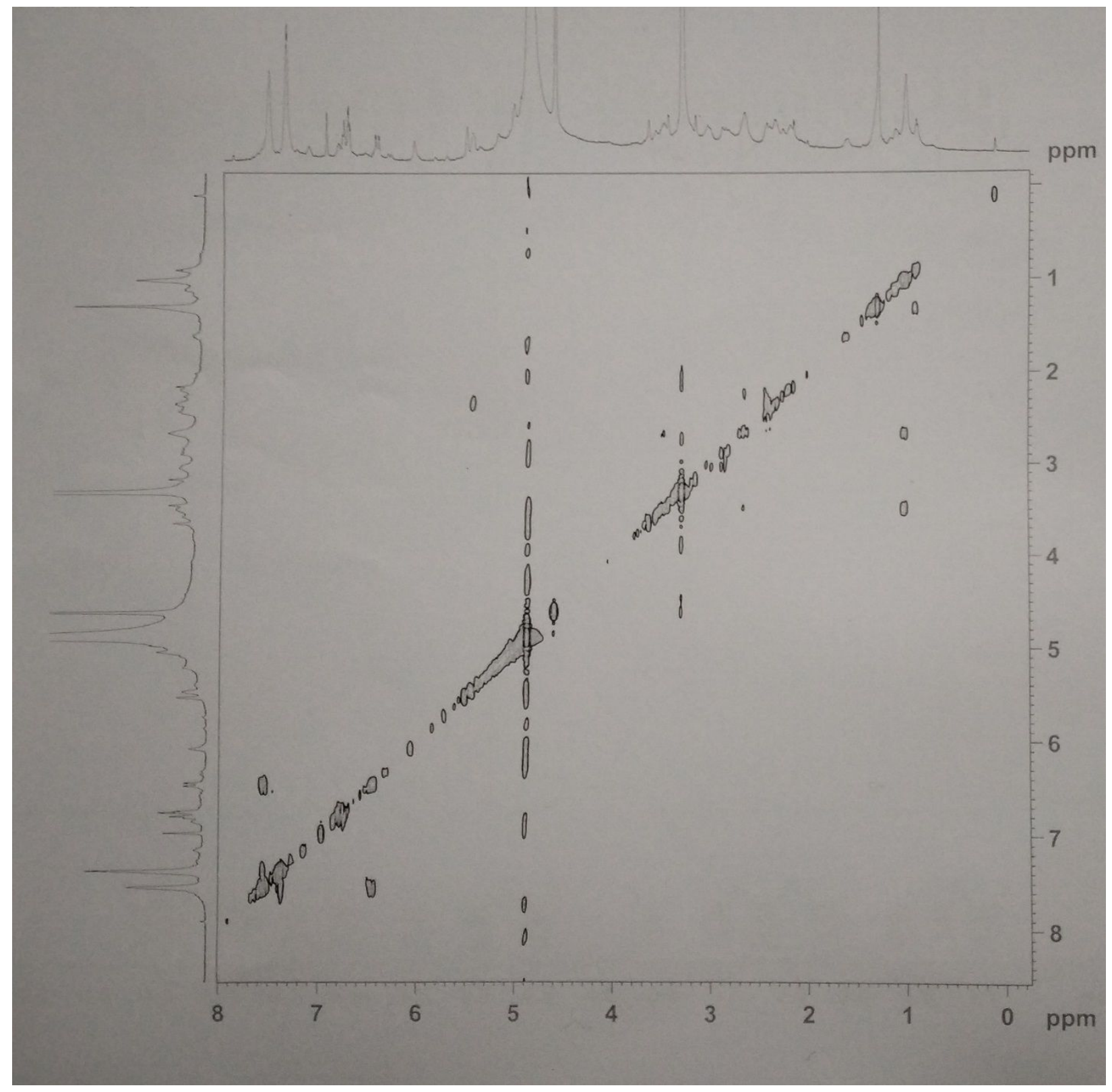

Figure Supporting 23. COSY of compound 5 in DMSO-d $\mathrm{d}_{6}$. 


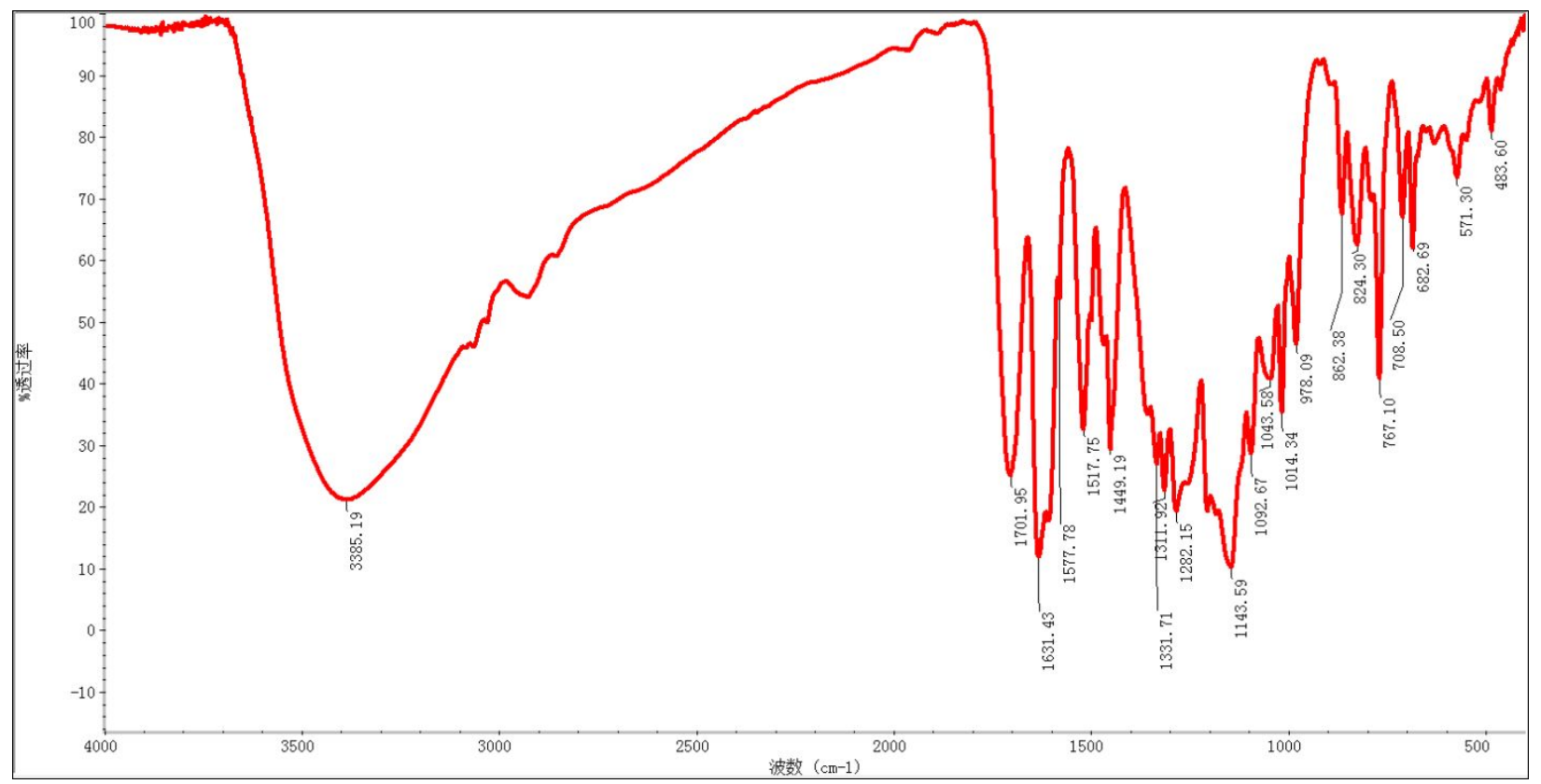

Figure Supporting 24. Infrared spectrum of compound 1.

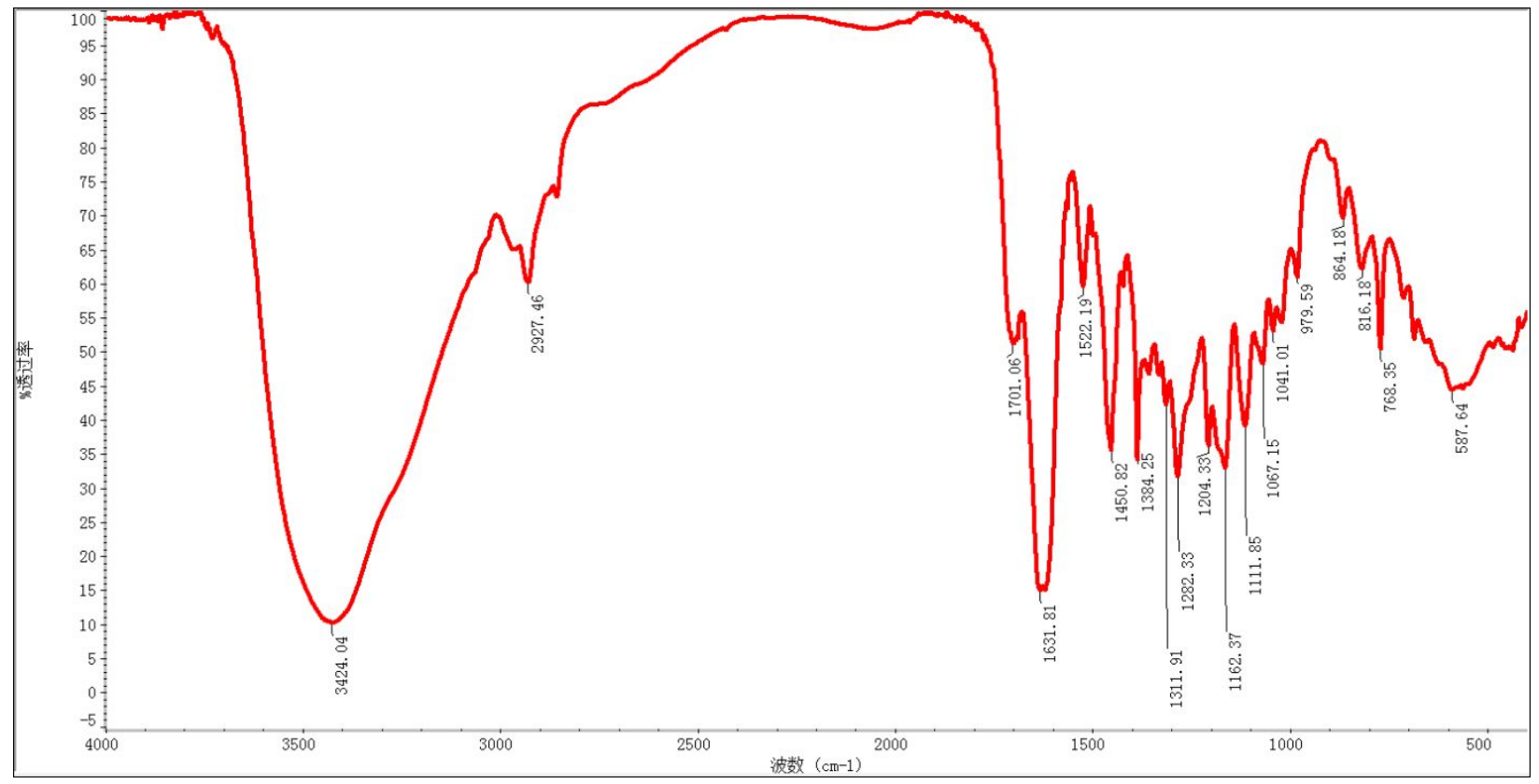

Figure Supporting 25. Infrared spectrum of compound 2. 


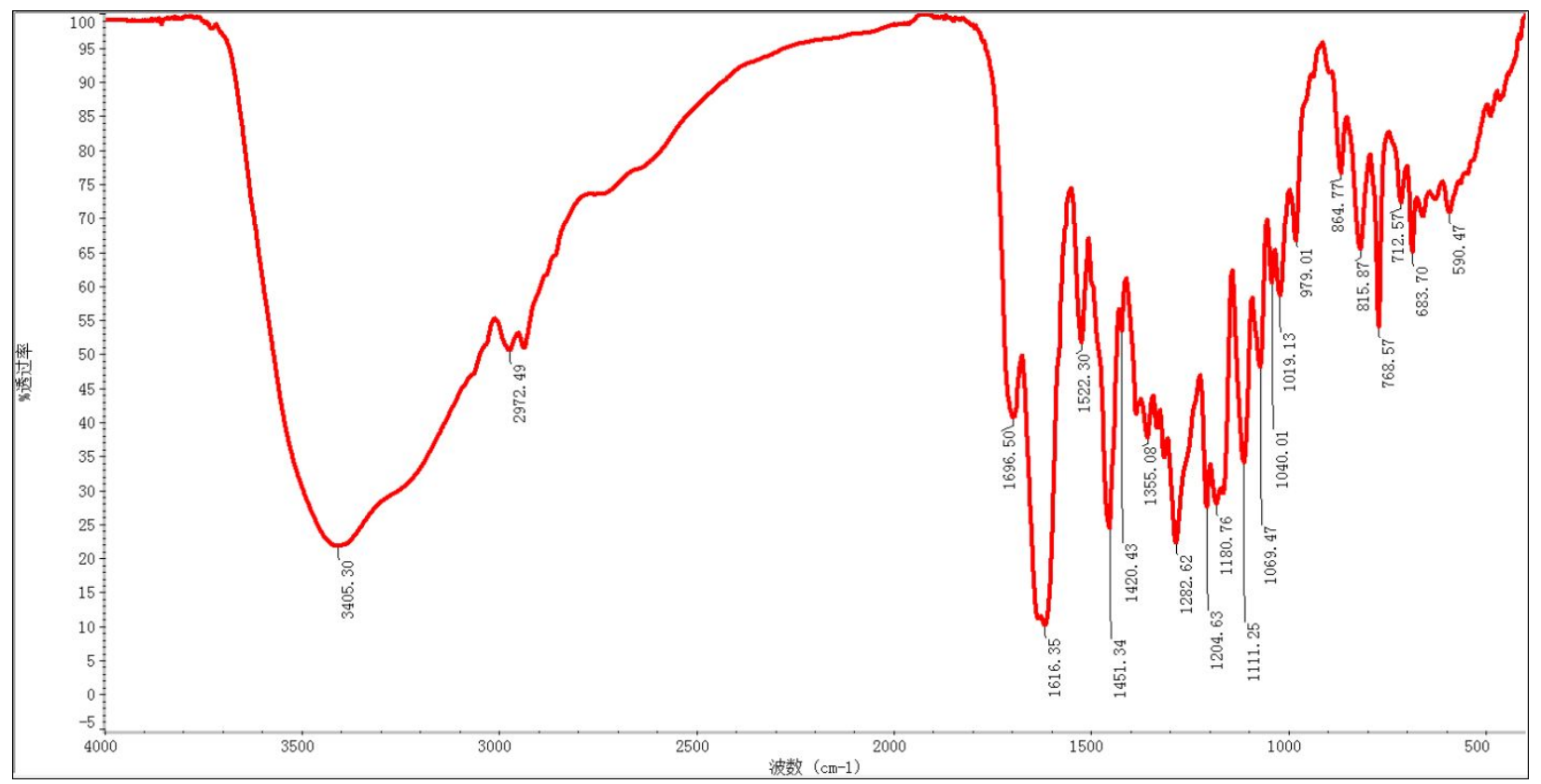

Figure Supporting 26. Infrared spectrum of compound 3.

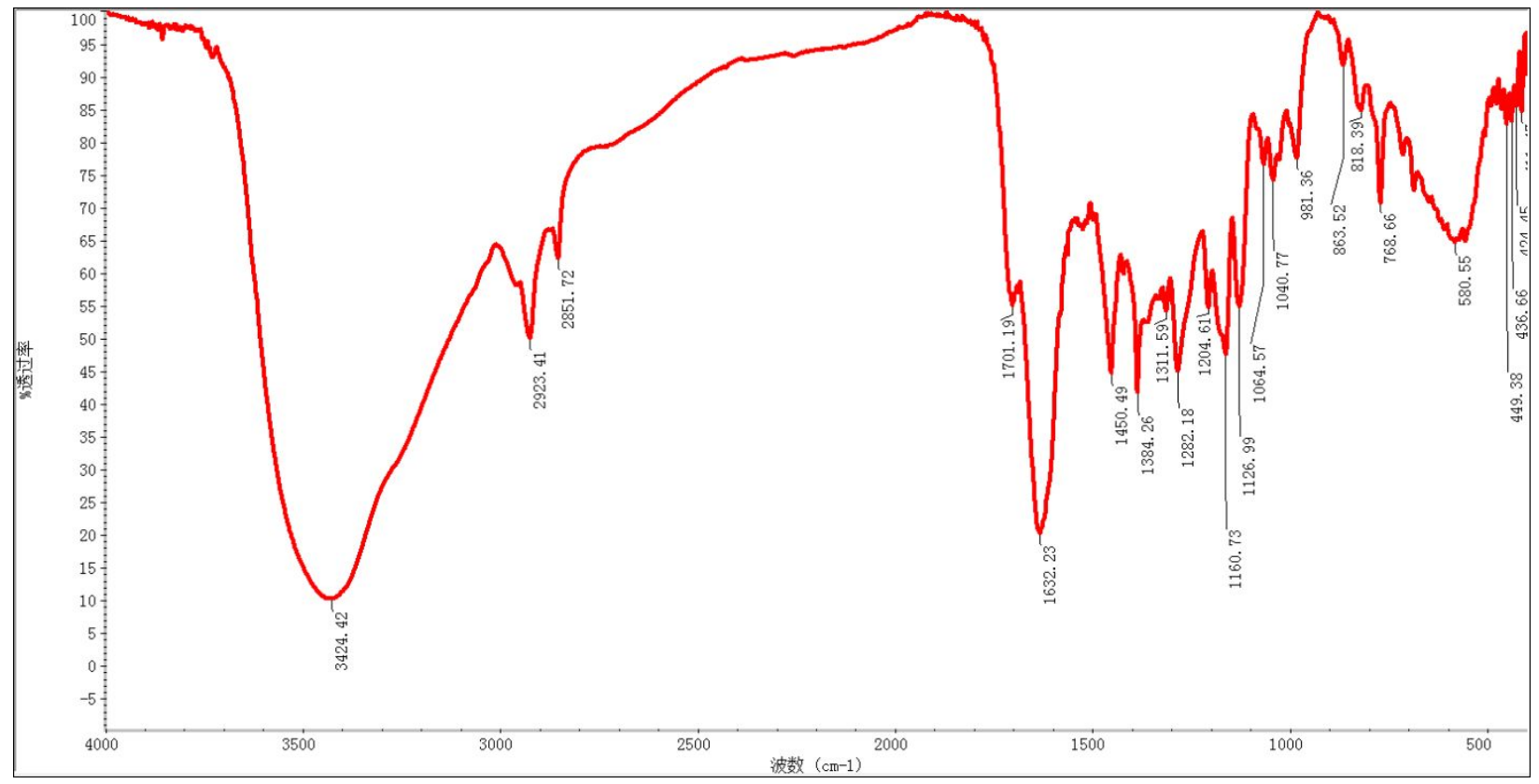

Figure Supporting 27. Infrared spectrum of compound 4. 


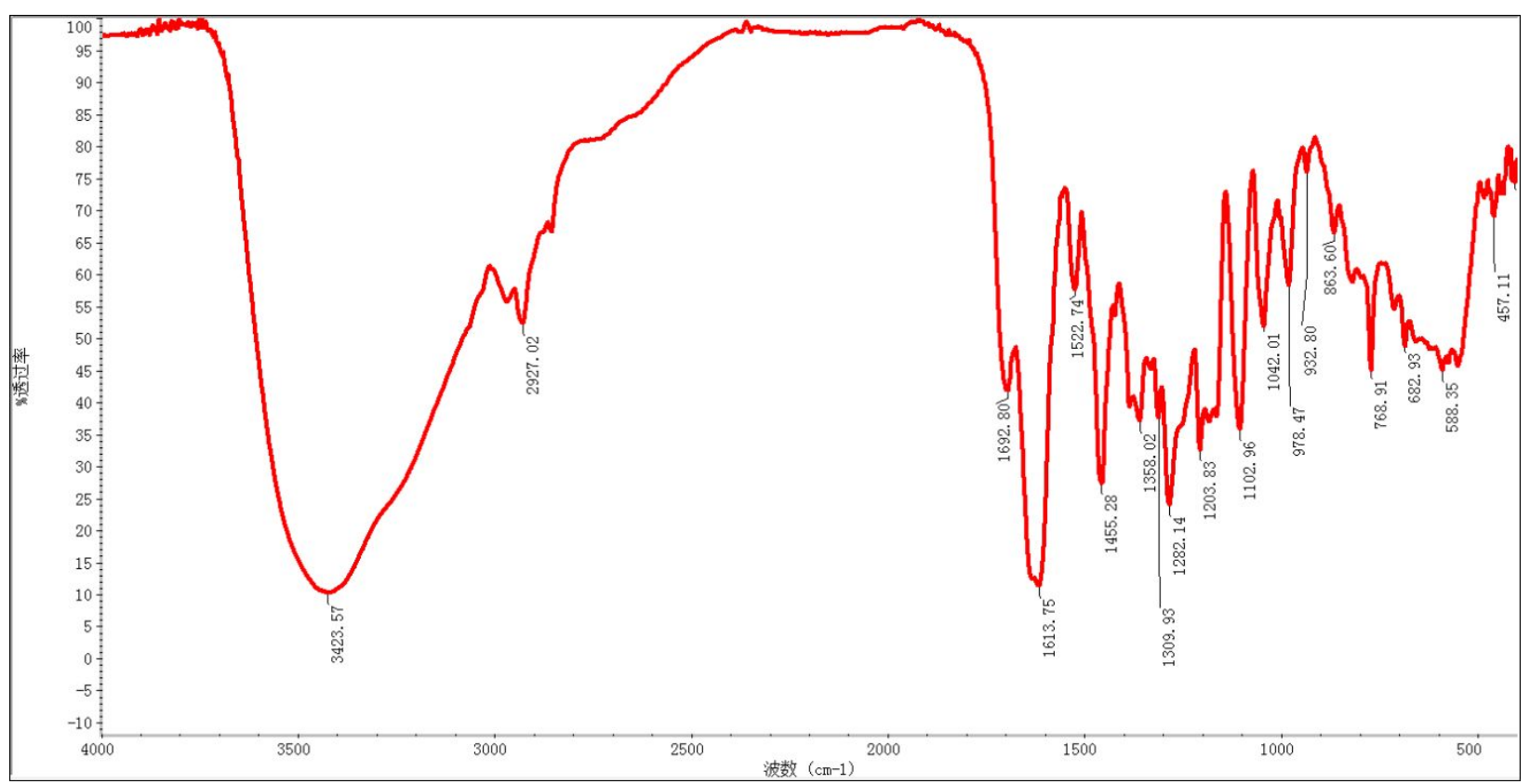

Figure Supporting 28. Infrared spectrum of compound 5.

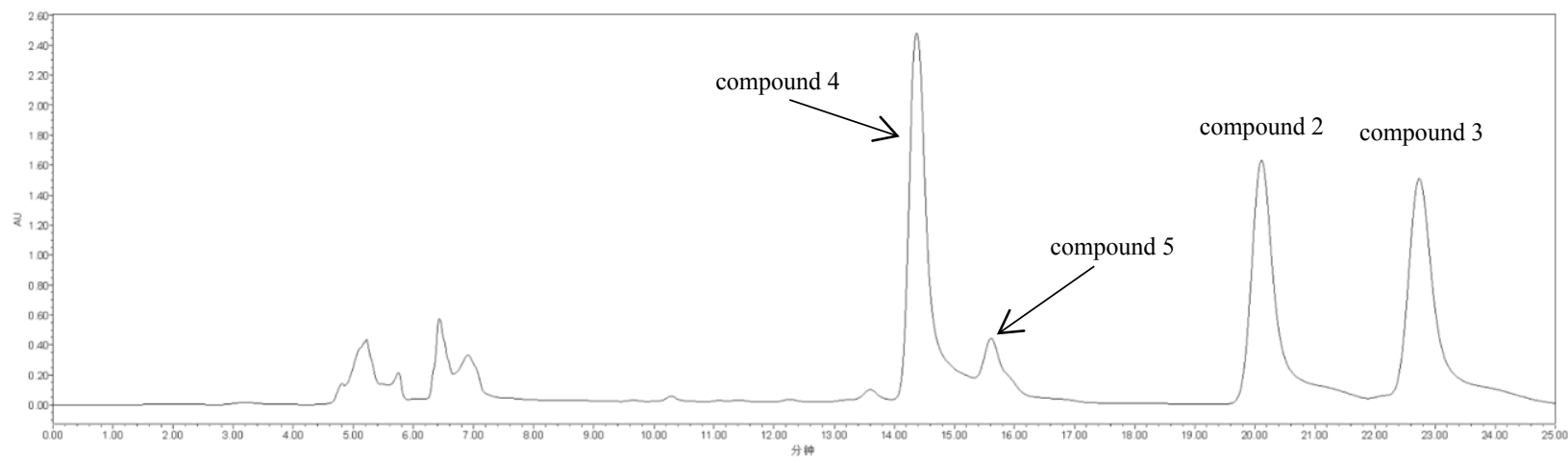

Figure Supporting 29. HPLC Preparation of compound 2-5 with UV detection at the waveleght $278 \mathrm{~nm}$.

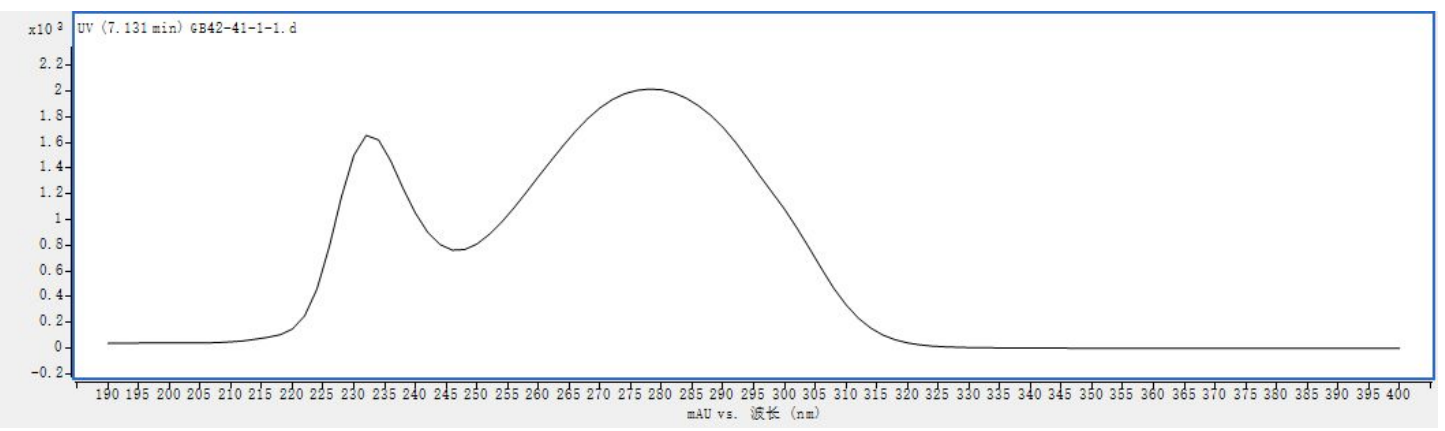


Figure Supporting 30. UV of Compound 1

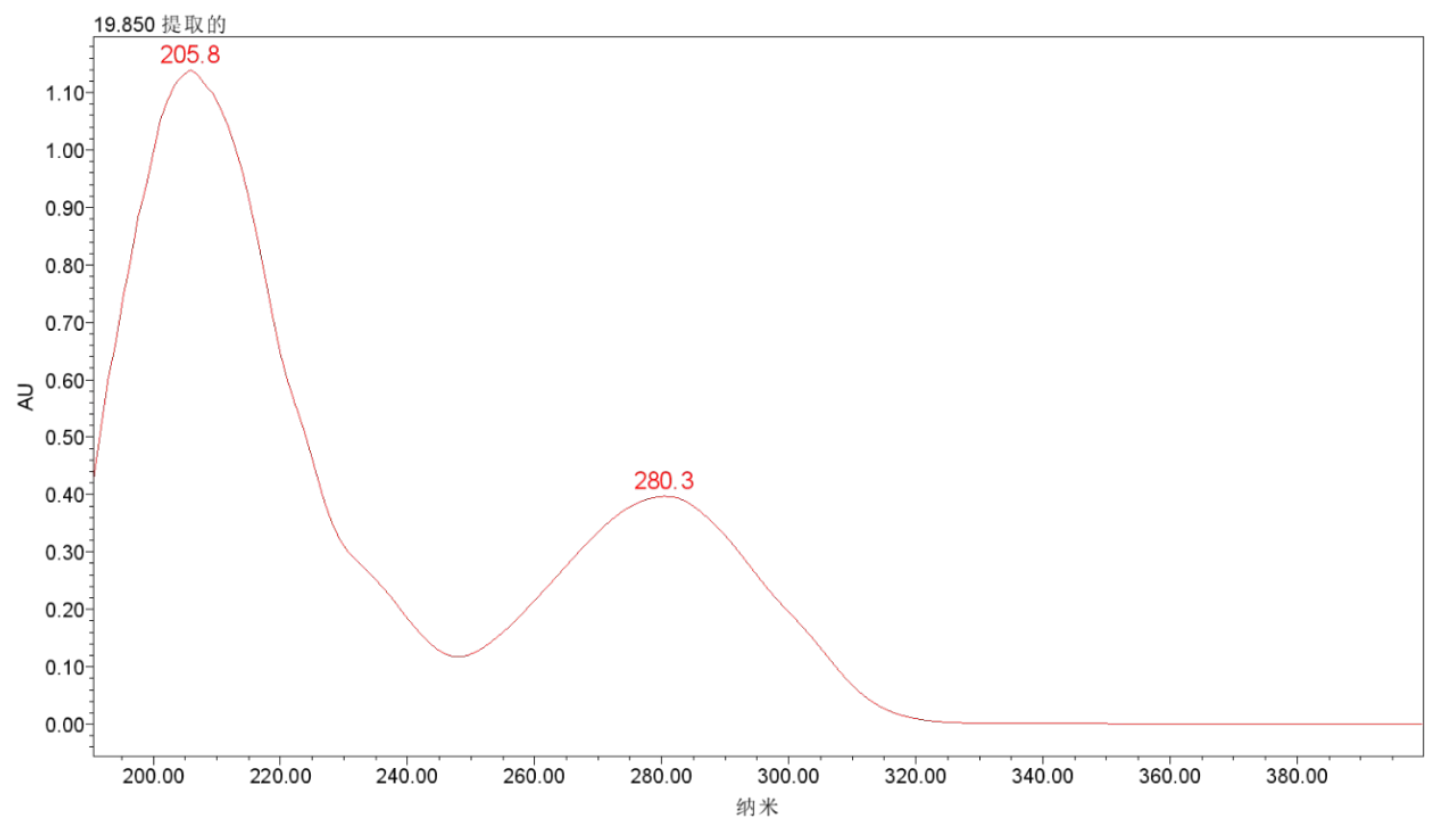

Figure Supporting 31. UV of Compound 2

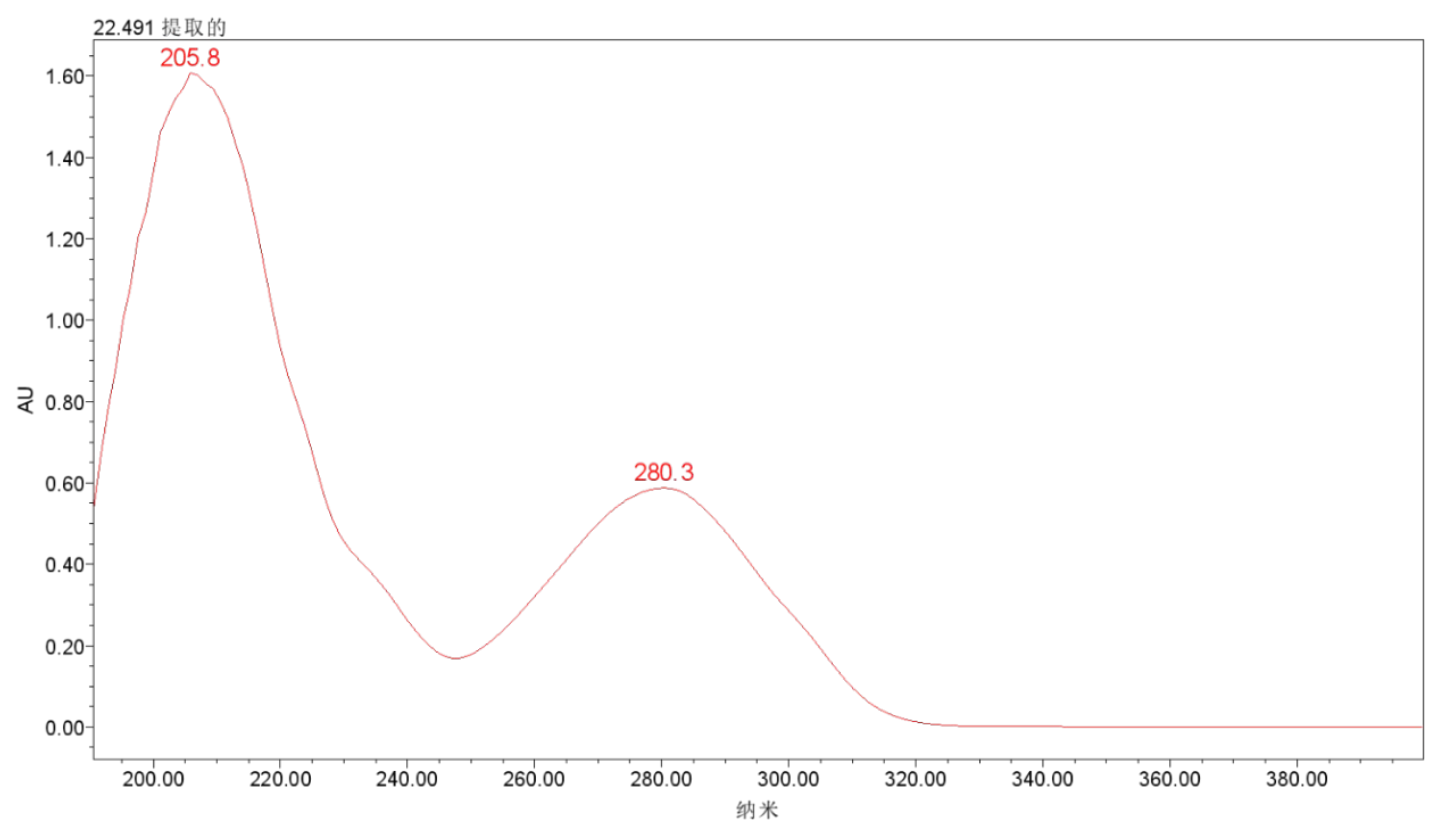

Figure Supporting 32. UV of Compound 3 


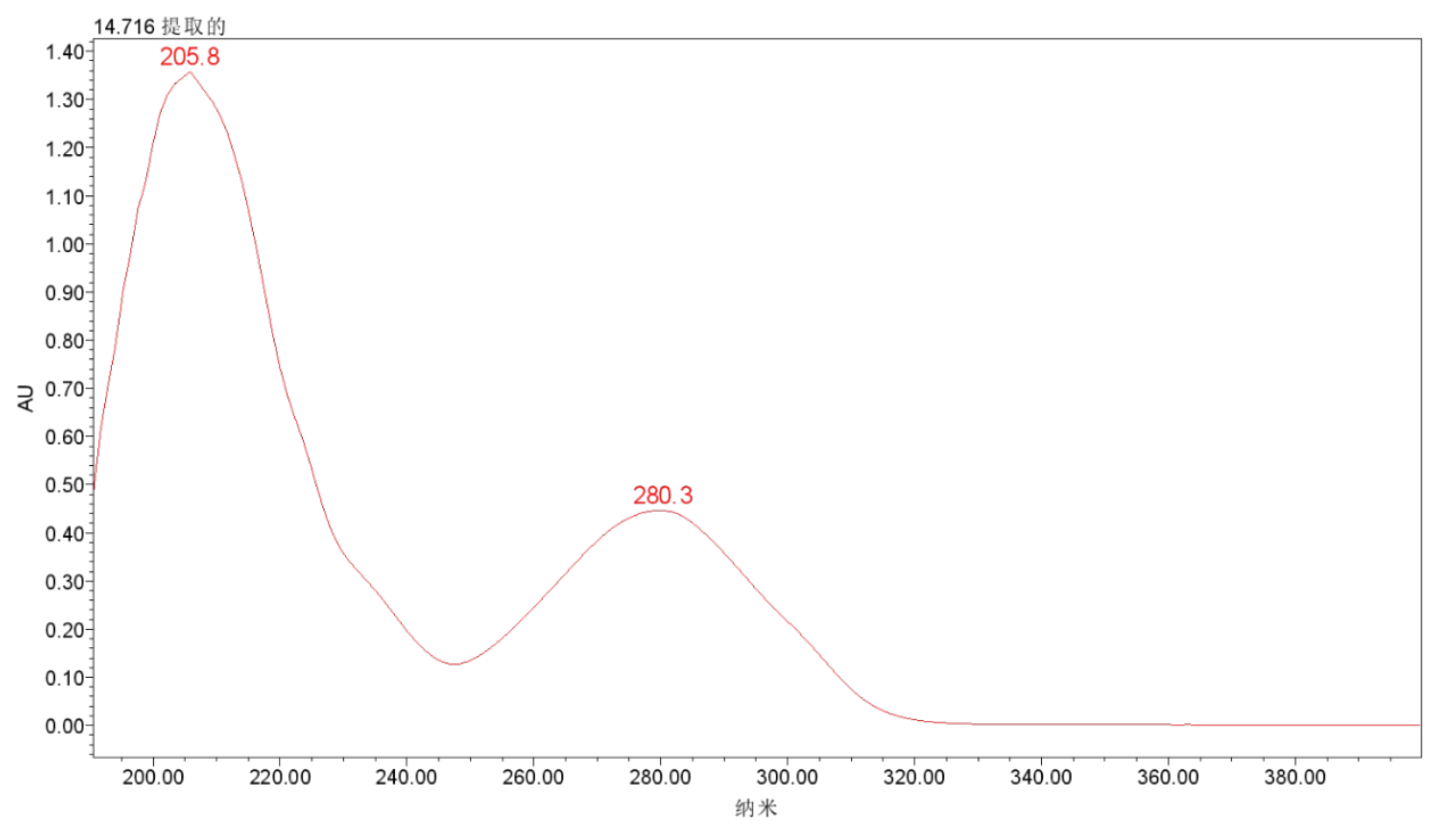

Figure Supporting 33. UV of Compound 4

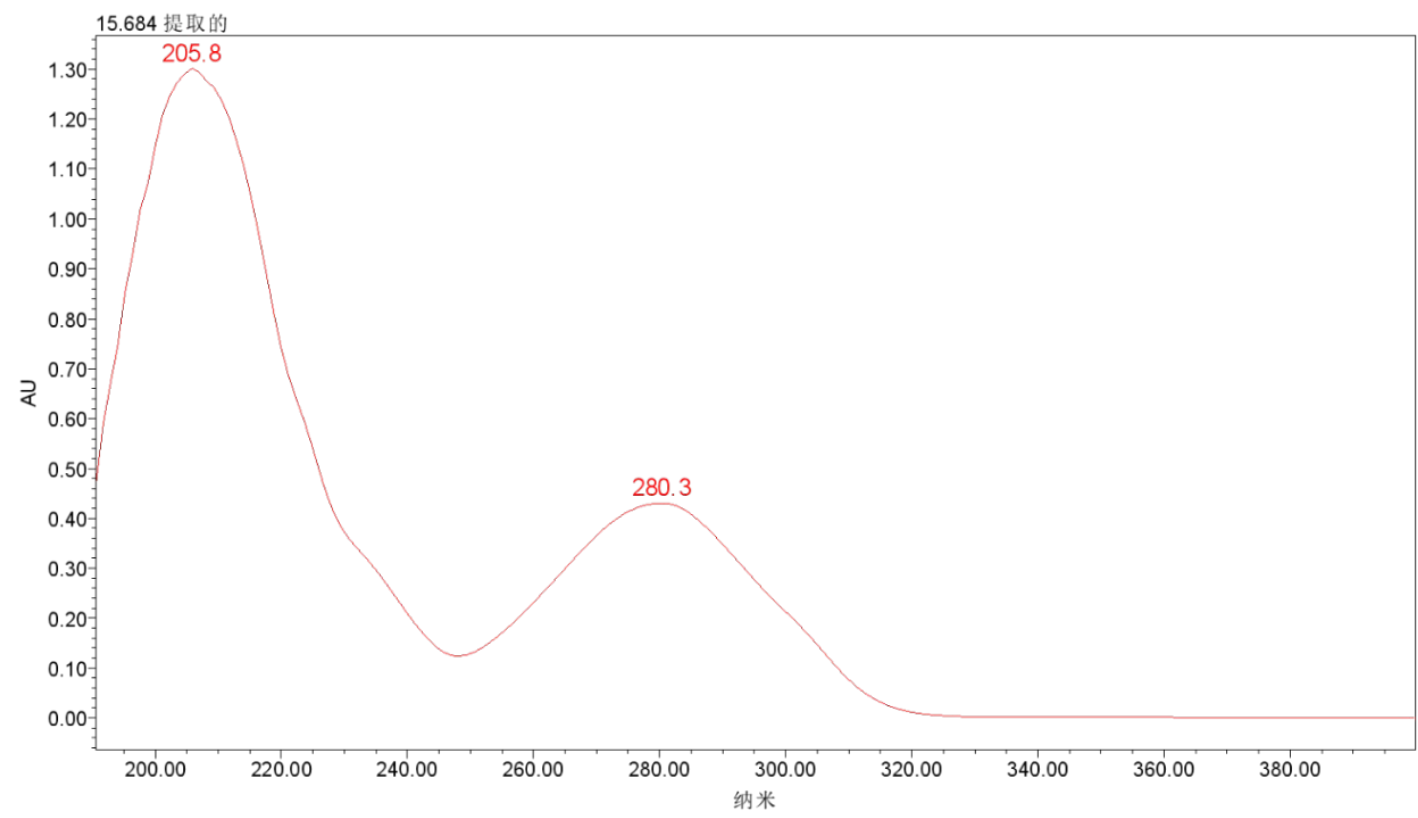

Figure Supporting 34. UV of Compound 5 


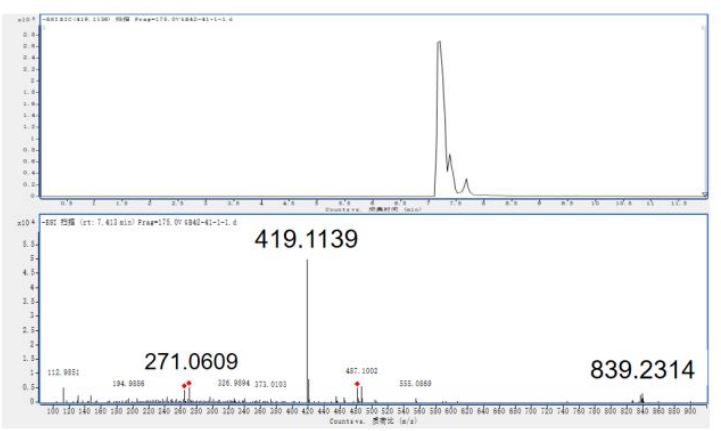

Figure Supporting 35. MS of Compound 1

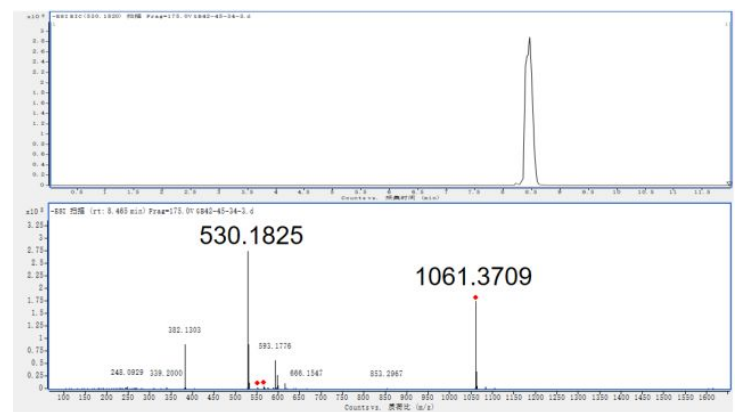

Figure Supporting 36. MS of Compound 2

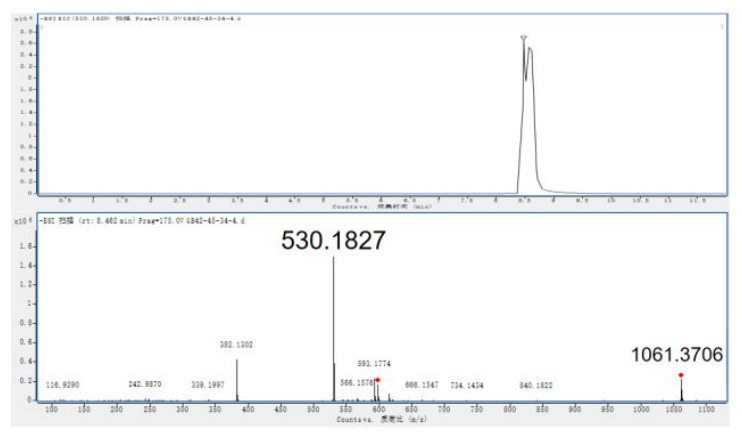

Figure Supporting 37. MS of Compound 3

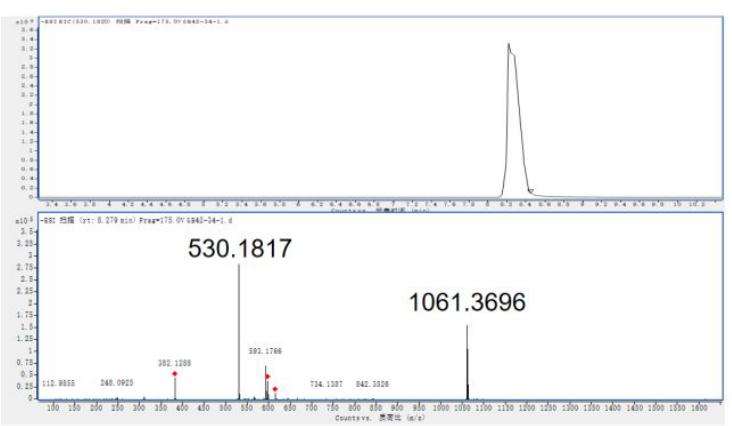

Figure Supporting 38. MS of Compound 4 


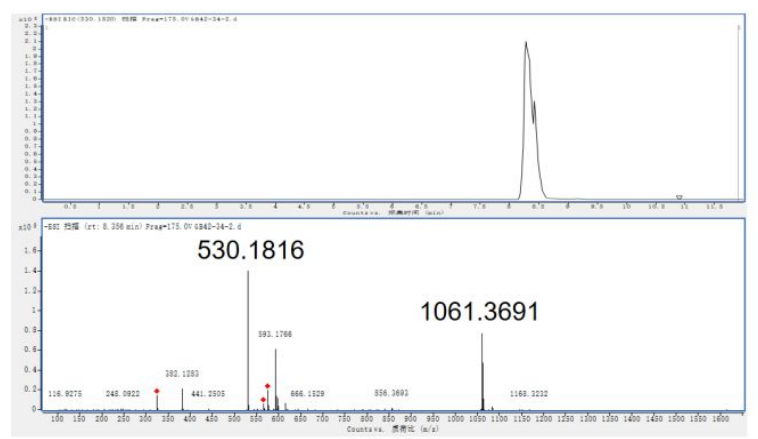

Figure Supporting 39. MS of Compound 5

Table 1. Preparative method for compound 2-5 by HPLC.

\begin{tabular}{llll}
\hline Time & Flow $(\mathrm{ml} / \mathrm{min})$ & $\mathrm{A} \%$ (water) & $\mathrm{B} \%$ (acetonitrile) \\
\hline 0 & 2 & 68 & 32 \\
30 & 2 & 68 & 32 \\
\hline
\end{tabular}

